\title{
Temporal shifts in recruitment dynamics of North Atlantic fish stocks: effects of spawning stock and temperature
}

\author{
Geir Ottersen ${ }^{1,2, *}$, Leif Christian Stige ${ }^{2}$, Joël M. Durant ${ }^{2}$, Kung-Sik Chan ${ }^{3}$, \\ Tristan A. Rouyer ${ }^{2,6}$, Kenneth F. Drinkwater ${ }^{4}$, Nils Chr. Stenseth ${ }^{2,5}$ \\ ${ }^{1}$ Institute of Marine Research, Gaustadalléen 21, 0349 Oslo, Norway \\ ${ }^{2}$ Centre for Ecological and Evolutionary Synthesis (CEES), Department of Biology, University of Oslo, PO Box 1066 Blindern, \\ 0316 Oslo, Norway \\ ${ }^{3}$ Department of Statistics and Actuarial Science, University of Iowa, Iowa City, Iowa 52242, USA \\ ${ }^{4}$ Institute of Marine Research, PB 1870 Nordnes, 5817 Bergen, Norway \\ ${ }^{5}$ Institute of Marine Research, Flødevigen Marine Research Station, 4817 His, Norway \\ ${ }^{6}$ Present address: IFREMER, UMR EME 212, Sète, France
}

\begin{abstract}
Effects of variation in spawning stock and sea temperature on long-term temporal patterns in recruitment dynamics of 38 commercially harvested fish stocks in the northern North Atlantic were studied. Different statistical models were explored within a Ricker stock-recruitment framework. This includes, in order of complexity, adding a linear temperature term, a nonlinear (smooth) temperature effect, and non-stationarities (trends in intercept or in temperature effect) and finally allowing for a stepwise change (a threshold). The different models were compared in a uniform approach using Akaike's information criterion corrected for small sample size as the model selection criterion. The relationship between recruitment, spawning stock biomass and temperature varied over time. The most frequent alteration in the non-stationary linear models was, for 14 stocks, in the intercept in recruitment success, suggesting a change in pre-recruit mortality over time. Threshold models performed better than the best linear or nonlinear stationary models for 27 of the stocks, suggesting that abrupt changes (maybe even regime shifts) are common. For half of the stocks studied, the temperature effect was statistically significant when added to the model of the relationship between recruitment success and spawning stock biomass. This includes all 6 of the herring stocks studied, with a positive effect for cold-water stocks and negative effect for stocks in the more temperate southern areas. For the 4 plaice stocks analysed, all located towards the centre of the overall distribution range of plaice, a tendency toward recruitment being favoured by lower temperatures was found.
\end{abstract}

KEY WORDS: Recruitment $\cdot$ Spawning stock biomass $\cdot$ Temperature $\cdot$ North Atlantic $\cdot$ Statistical modelling $\cdot$ Non-stationarity $\cdot$ Climate

Resale or republication not permitted without written consent of the publisher

\section{INTRODUCTION}

The quest toward understanding what regulates the variability in recruitment of commercially exploited fish stocks, i.e. the abundance of a cohort surviving to establish a new year-class, has been a 'search for the Holy Grail' in fisheries science since at least the early 20th century (Hjort 1914). Unfortunately, the answer still seems to be as elusive as the Grail itself, and despite progress, forecasting recruitment remains a formidable challenge (Houde 2008). Intuitively, there should be a quantitative relation- 
ship between the mature population and the recruits, i.e. stock-recruitment curves. However, although strong recruitment does tend to co-occur with high spawner abundance (Myers \& Barrowman 1996), the stock-recruitment relationship is frequently weak (Hilborn \& Walters 1992, Koslow 1992). There are several possible reasons for this seemingly weak link: (1) the influence of environmental variability (both interannual and long-term variation) on recruitment may make it difficult to identify stockrecruitment relationships, (2) not all stocks may have exhibited variation in stock size large enough to see a significant influence on recruitment, (3) there is uncertainty in the recruitment estimates (from e.g. virtual population analysis [VPA]), and (4) there are insufficient data. Still, a general denial of meaningful stock-recruitment relationships would have rather alarming consequences for the science of fish population dynamics (Iles 1994).

Density-dependent survival in the juvenile phase is generally believed to be of key importance in regulating the size of fish populations (Rothschild 1986, Vincenzi et al. 2012). Under this assumption, the emphasis is on quantifying the form of the densitydependence, which in turn determines the shape of the stock-recruitment relationship. This view is embodied in many age-structured fisheries assessment models in which regulation is effected through a stock-recruitment relationship (Hilborn \& Walters 1992). Further, it implies that recruitment may depend on the size of the parental stock in a nonlinear manner.

In contrast, density-independent environmental factors are also assumed to be of primary importance, accounting for most of the variability in pre-juvenile survival (Houde 2008). Paleo-record studies on fish abundance variability prior to the onset of extensive fishing indicate the importance of environmental factors for population regulation (Emeis et al. 2010, Finney et al. 2010). Actually, the importance of the environment for fluctuations in fish stocks was already acknowledged as early as the 1870s (Kendall \& Duker 1998). Since then, recruitment has been correlated with temperature in numerous studies on single stocks and fewer covering many stocks (examples of the latter are in Planque \& Fredou 1999, Fox et al. 2000, and Brunel \& Boucher 2007). Unfortunately, many such correlations tend to weaken or disappear when retested with extended data series (Myers 1998). Thus, unequivocal identification of the relative importance of density-dependent versus densityindependent factors underlying recruitment variations remains an enigma (Frank \& Leggett 1994).
Disentangling the effects of climate variability and internal population dynamics on recruitment by means of statistical data analysis is no easy task. For instance, indirect, interacting and nonlinear effects of environmental factors could lead to non-stationary behaviour of linear and additive models (e.g. Stige et al. 2006). Moreover, the inter-annual variability in temperature (or any other environmental variable) experienced by a single fish stock is often quite small (Brander 2000). These problems may be reduced by using long time series on many stocks in a comparative analysis, which should widen the thermal range and increase the number of degrees of freedom. The comparative analysis may be either a joint analysis, in which the results of identical analyses of individual stocks are compared, or a pooled analysis, in which the data are pooled and then analysed together (Brander 2000). Such studies can help to determine what is fundamental and what is specific to particular ecosystems for certain species (Drinkwater et al. 2010).

In the present paper, a comparative, joint approach is employed in statistically modelling temporal changes in recruitment dynamics in 38 commercially harvested fish stocks in the northern North Atlantic region, with a focus on the European side (see Table 1). We focus in particular on the possible non-stationarity in the long-term relationship between recruitment, spawning stock biomass (SSB) and temperature and on the effect of the population structure (SSB and body mass weighted mean age in the spawning stock [MA]) on the stockrecruitment relationship. Specifically, we examine the validity of the hypotheses given below. In each case, the formulation of the hypothesis is followed by a brief description of why we address this particular issue.

\section{H1: recruitment success varies among years in response to temperature}

Theory suggests that the environment (e.g. temperature) may modify the quantitative relationship between the mature population and the recruits, i.e. recruitment success $(\ln [R / \mathrm{SSB}]$, where $R$ is the number of recruits), and the stock-recruitment curves (Cushing \& Horwood 1994, Johansen 2007). While temperature-recruitment studies are numerous, far fewer have analysed the joint effects of temperature and stock size on recruitment. Exceptions include work on Baltic cod Gadus morhua and sprat Sprattus sprattus (Köster et al. 2003), red mullet Mullus barba- 
tus in the Strait of Sicily (Levi et al. 2003), and North Sea cod (Olsen et al. 2011). Moreover, if effects of interannual differences in temperature are not accounted for, apparent nonstationarity in the stockrecruitment relationship may result.

\section{H2: the relationship between recruitment, SSB, and temperature is not constant over time}

This implies that the recruitment dynamics is non-stationary, either with a gradual alteration or a more abrupt temporal shift, with different dynamics before and after this shift. Such shifts may be part of broader ecological regime shifts, which have been defined as 'large, abrupt, persistent changes in the structure and function of a system' (Biggs et al. 2009). Marine ecological regime shifts have been described in numerous earlier publications, including Francis \& Hare (1994) regarding the Northeast Pacific and Beaugrand (2004) regarding the North Sea.

Myers (1998) re-examined previously published environment-recruitment correlations with prolonged data series and found that the proportion of published correlations that could be verified upon retest was low. The original findings could be merely statistical artefacts, but real changes in underlying regulating processes may have taken place, altering the observed relationships. Indeed, long-term changes in the ecosystem, for example in response to climate change or harvesting, could lead to changes in the relative roles of the different abiotic and biotic factors that influence juvenile fish survival and thus the relationships studied here. For example, increased abundance of predators on juveniles could lead to diminished importance of abiotic factors (Bailey 2000).

For stocks that displayed a statistically significant temporal shift in recruitment dynamics, we examined possible causes for these shifts, formulated as Hypotheses H3, H4, and H5.

\section{H3: recruitment per SSB decreases with decreasing MA}

High exploitation levels of many marine fish populations usually result in a disproportional loss of the largest (and thus oldest) individuals. Consequently, a juvenated, age-truncated spawning stock has been suggested as a potential problem for long-lived fish (Law 1991, Berkeley et al. 2004, Planque et al. 2010).
The concern about stock juvenation largely stems from its potential impairment of recruitment success (e.g. Ponomarenko 1973, Beamish et al. 2006). Especially for cod, there is a considerable literature, which collectively indicates that the proportion of larger (and thus older) fish present in a population may contribute considerably toward determining the number of eggs, larvae, and subsequently successful recruits. Larger females tend to produce more eggs per gram of body weight (Marteinsdottir \& Thorarinsson 1998) and also to produce eggs that have a wider range of vertical distribution, thus causing broader horizontal dispersion (Kjesbu et al. 1992). Further, the size of cod eggs and larvae generally increases with maternal size (Chambers \& Waiwood 1996, Trippel et al. 1997), also increasing viability, as both field studies (Meekan \& Fortier 1996) and theory (Houde 1987) suggest a tendency toward increased survival among faster-growing larvae.

\section{H4: recruitment per SSB decreases with long-term reduction in SSB}

While the Ricker model predicts that recruitment per SSB is higher at low SSB because of reduced intraspecific competition, we hypothesize that a long-term reduction in SSB has the opposite effect. Although this may seem counterintuitive, several mechanisms could cause such an outcome. First, in the ocean, it is common for prey fishes to eat the eggs and larvae of the predators that prey on them. When a dominant predator population declines due to an external impact, such as fishing or climatic variation, it is logical that its favoured prey, if not equally impacted, should increase in abundance. Thus, an observed reduction in SSB (of, e.g., cod) may have resulted in a lessened predation pressure on fishes that prey on cod eggs and larvae. This again should cause increased predation on early life stages of cod and thus decreased survival until recruitment (prey to predator feedback loop; Bakun 2010). Depensatory effects can then delay or prevent stock rebuilding (Walters \& Kitchell 2001), resulting in a prolonged period of reduced SSB.

Secondly, a long-term reduction in SSB may be associated with loss of spatial and genetic structure in the populations, for example through the loss of geographically separated subunits of the stocks. The eggs and larvae of such 'unstructured' stocks are likely to experience more uniform environmental conditions compared to the eggs and larvae from more 'pristine' stocks (Ciannelli et al. 2013, this vol- 
Table 1. Species, stock identification, location, number of data points where all necessary (population and temperature) data are available, and results from linear non-stationary and stationary models (see 'Materials and methods', Eqs. 2-5). Temp.: sign $(+$ or -$)$ of the temperature effect in Eq. (2) with corresponding statistical significance. Effect: form of temperature effect in best model as evaluated by the corrected Akaike's information criterion $\left(\mathrm{AIC}_{\mathrm{C}}\right)$ with corresponding statistical significance. Year: sign and statistical significance of the year effect in Eq. (4). A year effect indicates a change in the intercept. Year.temp: sign and statistical significance of the Temp $\times$ Year effect in Eq. (5). Significant year.temp effect indicates a temporal trend in the temperature effect. $\mathrm{dAIC}_{\mathrm{C}}$ : difference in $\mathrm{AIC}_{\mathrm{C}}$ between the best non-stationary linear and stationary model. Species: cod Gadus morhua, haddock Melanogrammus aeglefinus, herring Clupea harengus, plaice Pleuronectes platessa, saithe Pollachius virens, sole Solea solea, whiting Merlangius merlangus. ${ }^{*} \mathrm{p}<0.05,{ }^{* *} \mathrm{p}<0.01$ (F-tests on nested models with and without variable)

\begin{tabular}{|c|c|c|c|c|c|c|c|}
\hline Species and stock & Location & $\mathrm{N}$ & Temp. & Effect & Year & Year.temp & $\mathrm{dAIC}_{\mathrm{C}}$ \\
\hline $\mathrm{Cod} 3 \mathrm{NO}^{\mathrm{a}}$ & Southern Grand Bank & 49 & + & None & $-{ }^{* *}$ & $+^{* *}$ & -25.6 \\
\hline Cod $3 P n 4 R^{b}$ & Northern Gulf of St. Lawrence & 33 & + & None & $-^{*}$ & + & -1.0 \\
\hline $\operatorname{Cod} 4 \mathrm{TVn}^{\mathrm{c}}$ & Southern Gulf of St. Lawrence & 36 & + & None & $-{ }^{* *}$ & + & -6.0 \\
\hline $\operatorname{Cod} 4 X^{\mathrm{d}}$ & Western Scotian Shelf & 28 & - & None & $-^{*}$ & - & -4.0 \\
\hline Cod 5Zjme & Eastern Georges Bank & 31 & + & None & - & - & 0.8 \\
\hline Cod Baltic 22-24 & Western Baltic Sea & 39 & - & Nonlinear** & $-{ }^{* *}$ & - & -0.9 \\
\hline Cod Baltic 25-32 & Baltic Sea proper & 41 & + & None & - & $+^{* *}$ & -9.0 \\
\hline Cod Faroe Plateau & Faroe Plateau & 46 & $-{ }^{* *}$ & Linear** & - & - & -1.6 \\
\hline Cod Iceland & Icelandic waters & 54 & $-{ }^{*}$ & Linear* & - & + & -1.1 \\
\hline Cod North Sea & North Sea & 45 & $-{ }^{* *}$ & Linear** & + & + & 2.4 \\
\hline Cod Northeast Arctic & Barents Sea & 83 & + & None & $+^{*}$ & + & -2.7 \\
\hline Cod VIa & West of Scotland & 29 & - & None & - & + & -1.7 \\
\hline Cod VIIa & Irish Sea & 40 & $-{ }^{* *}$ & Linear** & - & - & -1.8 \\
\hline Cod VIIek & $\begin{array}{l}\text { Western English Channel } \\
\text { and SW of Ireland }\end{array}$ & 36 & - & Nonlinear & $+^{* *}$ & + & -11.8 \\
\hline Haddock Arctic & Barents Sea & 56 & $+{ }^{* *}$ & Linear** & + & + & 1.9 \\
\hline Haddock Faroe Plateau & Faroese waters & 52 & - & None & $-{ }^{*}$ & - & -4.5 \\
\hline Haddock Iceland & Icelandic waters & 29 & $++^{* *}$ & Nonlinear** & + & - & 0.8 \\
\hline Haddock North Sea & North Sea & 46 & - & Nonlinear** & $-^{*}$ & $-{ }^{*}$ & -1.1 \\
\hline Haddock VIa & West of Scotland & 29 & - & None & - & - & 1.1 \\
\hline Herring Baltic 25-32 & Baltic Sea proper & 34 & $+{ }^{* *}$ & Linear** & - & + & 1.2 \\
\hline Herring Baltic 30 & Bothnian Sea (Baltic) & 35 & $+^{*}$ & Linear* & $+^{*}$ & - & -3.5 \\
\hline Herring Baltic Riga Bay & Riga Bay (Baltic) & 31 & $++^{* *}$ & Linear** & - & - & 1.6 \\
\hline Herring North Sea & North Sea & 49 & $-{ }^{* *}$ & Linear** & + & - & -1.2 \\
\hline Herring Norweg. SS & $\begin{array}{l}\text { Norwegian and Barents Sea } \\
\text { (Norwegian spring-spawning) }\end{array}$ & 86 & $+^{* *}$ & Nonlinear** & - & - & -1.6 \\
\hline Herring VIa & West of Scotland & 51 & $-{ }^{* *}$ & Nonlinear** & - & - & 2.7 \\
\hline Plaice North Sea & North Sea & 51 & $-{ }^{* *}$ & Nonlinear** & $+{ }^{* *}$ & - & 0.0 \\
\hline Plaice VIIa & Irish Sea & 42 & $-{ }^{* *}$ & Linear** & $-{ }^{* *}$ & + & -9.7 \\
\hline Plaice VIId & Eastern English Channel & 28 & - & Nonlinear* & + & + & 5.7 \\
\hline Plaice VIIe & Western English Channel & 31 & $-{ }^{* *}$ & Nonlinear** & + & + & 2.7 \\
\hline Saithe Faroe & Faroese waters & 45 & $+^{*}$ & Linear* & + & - & -0.7 \\
\hline Saithe Iceland & Icelandic waters & 34 & + & None & - & + & 1.3 \\
\hline Saithe 3a46 & North Sea and west of Scotland & 39 & + & None & $-{ }^{*}$ & - & -2.1 \\
\hline Saithe Northeast Arctic & Barents Sea & 46 & $+^{*}$ & Nonlinear* & + & + & -0.6 \\
\hline Sole North Sea & North Sea & 51 & - & None & + & + & 1.9 \\
\hline Sole VIIa & Irish Sea & 35 & + & None & $--^{* *}$ & $-{ }^{*}$ & -10.0 \\
\hline Sole VIIe & Western English Channel & 38 & $+{ }^{* *}$ & Nonlinear* & + & + & 1.6 \\
\hline Sole VIIfg & Celtic Sea & 36 & + & Linear & - & - & 1.4 \\
\hline Whiting VIIek & $\begin{array}{l}\text { Western English Channel } \\
\text { and SW of Ireland }\end{array}$ & 26 & - & Linear & + & - & 2.6 \\
\hline
\end{tabular}

ume). As a consequence of reduced opportunities for 'bet-hedging' (Hsieh et al. 2010), a stock in this state may be hit harder during years with unfavourable environmental conditions, with lower egg and larval survival and subsequently reduced recruitment. In contrast, stock state may be less important in years with environmental conditions favourable for high egg and larval survival, when a sufficient number in any case survive through these stages, and recruitment may be more limited by compensatory density dependence in juvenile survival. 


\section{H5: recruitment per SSB changes with long-term changes in temperature}

Long-term change in temperature is here taken as a proxy for a change in climate regime, with a potentially different ecological effect than short-term fluctuations. Ecosystem regime shifts (as briefly described under H3 above) are often linked to climate but can also be driven by anthropogenic forcing, such as heavy fishing or pollution (Bakun 2004). Examples of shifts in climate regime that have had pronounced ecological impact on the study area of the present paper include the warming of the northern North Atlantic Ocean during the 1920s and 1930s (Drinkwater 2006) and the ecosystem regime shift in the North Sea during 1982 to 1988 , which are related to pronounced changes in large-scale hydro-meteorological forcing (Beaugrand 2004).

Finally, for the stocks that displayed a statistically significant temporal shift in recruitment dynamics and an effect of temperature in at least one of the 2 periods, we examined how the strength of the temperature effect changed between the periods. Specifically, we explored how this change corresponded to the changes in respective body mass-weighted mean age of the spawning stock (MA) and SSB, as formulated in Hypotheses $\mathrm{H} 6$ and $\mathrm{H} 7$.

\section{H6: the temperature-recruitment relationship strengthens with decreasing MA}

Juvenation of the parent stock has caused concern since this could potentially affect recruitment by making it more susceptible to environmental fluctuations (e.g. Ponomarenko 1973, Beamish et al. 2006). H6 was examined for Northeast Arctic cod by Ottersen et al. (2006). They found statistical substantiation for the climate-recruitment link strengthening with reduced age of spawners and suggested this may be a more general mechanism. The idea has been supported by several recent reviews, e.g. Brander (2010), Hsieh et al. (2010), and Planque et al. (2010). Here, we wish to examine if there is general evidence for this suggestion or if it is restricted to particular groups of fish, for instance naturally long-lived stocks.

\section{H7: the temperature-recruitment relationship strengthens with decreasing SSB}

It has been proposed that the relationship between the environment (e.g. temperature) and recruitment may be affected by the size of the parent stock. For example, Brander (2005a) examined all cod stocks on the European Shelf south of $62^{\circ} \mathrm{N}$ and found that environmental variability (in this case the North Atlantic Oscillation [NAO]) only has a noteworthy effect on recruitment when the spawning stock is low.

If we assume that a low SSB is connected with a generally decreased stock size, one possible mechanism is the decrease of density dependent regulation. Density dependent processes are expected to stabilise recruitment variations (e.g. Vincenzi et al. 2012). Lighter density dependent control may hence lead to stronger influence of density independent processes, and a result of that may be an increased link between recruitment and temperature.

Further, at low population size, a stock may lose spatial and/or genetic diversity through selection of certain population sub-units within metapopulations, which may reduce the buffering capacity of the population in response to environmental fluctuations (Hsieh et al. 2010, Planque et al. 2010, Ciannelli et al. 2013).

\section{MATERIALS AND METHODS}

\section{Fish population data}

For each of the fish stocks studied, the geographical area, the length of the period with available time series for all of the SSB, number of recruits $(R)$, and MA are given in Table 1, while the actual years covered for each stock are found in Table 2 . The time series of recruitment and SSB of the 38 stocks analysed are shown in Fig. 1. For 33 northeast Atlantic stocks, the population data were extracted from the latest reports made available by the relevant working groups at the International Council for the Exploration of the Sea (ICES, www.ices.dk). For 5 Northwest Atlantic cod stocks, the population data were extracted from the most recent available papers and reports or through personal communication (for references, see Table 1 ).

Fish population values were used as estimated in previously published results, mainly from VPA which is based upon commercial catch statistics; recent years are typically tuned by scientific surveys, often by means of extended survivor analysis (XSA; Shepherd 1999). We are aware of potential problems with the use of VPA, especially for recruitment estimates. These problems include the assumptions of constant natural mortality and 
Table 2. Characteristics of stocks with a statistically significant temporal shift in recruitment dynamics (see 'Materials and methods', Eq. 6). Period: period from year of spawning to last year of data. Shift: if the best model (lowest corrected Akaike's information criterion $\left[\mathrm{AIC}_{\mathrm{C}}\right]$ ) for the stock includes a threshold, separating the time-series into 2 periods, the first year of the second 'regime' is given. Asterisk indicates statistical significance of threshold. dInt: change in Intercept (ln[R/SSB]) from Regime 1 to Regime 2, with standard error in parentheses and statistical significance. R: no. of recruits; SSB: spawning stock biomass. T1: coefficient for temperature effect in first regime with standard error and statistical significance (if term selected in model with lowest $\mathrm{AIC}_{\mathrm{C}}$ ). T2: temperature effect in second regime. T1+2: common temperature effect for whole period (nl: nonlinear). $\mathrm{dAIC}_{\mathrm{C}}$ : difference in $\mathrm{AIC}_{\mathrm{C}}$ between best threshold and best stationary model. These values are directly comparable to the corresponding values in Table 1 (for non-stationary linear models). ${ }^{*} \mathrm{p}<0.05,{ }^{* *} \mathrm{p}<0.01$

\begin{tabular}{|c|c|c|c|c|c|c|c|}
\hline Species and stock & Period & Shift & dInt & $\mathrm{T} 1$ & $\mathrm{~T} 2$ & $\mathrm{~T} 1+2$ & $\mathrm{dAIC}_{\mathrm{C}}$ \\
\hline Cod 3NO & $1959-2007$ & $1983^{* *}$ & $-2.01(0.27)^{* *}$ & & $0.42(0.18)^{*}$ & & -33.9 \\
\hline Cod 3Pn4RS & $1974-2006$ & $1984^{* *}$ & $-1.03(0.22)^{* *}$ & & & & -14 \\
\hline Cod 4TVn & $1971-2006$ & $1985^{* *}$ & $-0.62(0.16)^{* *}$ & & & & -9.2 \\
\hline Cod $4 \mathrm{X}$ & $1980-2007$ & 1995 & $-0.66(0.24)^{*}$ & & & & -2.9 \\
\hline Cod 5Zjm & $1978-2008$ & 1991 & $-1.5(0.48)^{* *}$ & & & & -4.9 \\
\hline Cod Baltic 22-24 & $1970-2008$ & & & & & $\mathrm{nl}^{* *}$ & 1.1 \\
\hline Cod Baltic 25-32 & $1966-2006$ & $1986^{* *}$ & $-0.8(0.16)^{* *}$ & $-0.52(0.24)^{*}$ & $0.26(0.16)$ & & -17.9 \\
\hline Cod Faroe Plateau & $1961-2006$ & $1983^{*}$ & $-0.55(0.17)^{* *}$ & & & $-1.05(0.29)^{* *}$ & -6 \\
\hline Cod Iceland & $1955-2008$ & 1986 & $-0.35(0.1)^{* *}$ & & & & -3.2 \\
\hline Cod North Sea & $1963-2007$ & 1984 & $-0.85(0.35)^{*}$ & & & $-0.71(0.17)^{* *}$ & -1.6 \\
\hline Cod Northeast Arctic & $1921-2003$ & $1947^{* *}$ & $0.58(0.15)^{* *}$ & & $0.26(0.16)$ & & -11.6 \\
\hline Cod VIa & $1978-2006$ & & & & & & 1.6 \\
\hline Cod VIIa & $1968-2007$ & 1992 & $-0.83(0.33)^{*}$ & & & $-0.89(0.24)^{* *}$ & -2 \\
\hline Cod VIIek & $1971-2006$ & $1982^{* *}$ & $1.55(0.36)^{* *}$ & $-2.76(0.95)^{* *}$ & $-0.81(0.32)^{*}$ & & -9.7 \\
\hline Haddock arctic & 1950-2005 & 1970 & $-0.24(0.28)$ & & $1.23(0.33)^{* *}$ & & -1.6 \\
\hline Haddock Faroe Plateau & $1957-2008$ & $1977^{*}$ & $-0.95(0.26)^{* *}$ & & & & -8.3 \\
\hline Haddock Iceland & $1979-2007$ & & & & & $\mathrm{nl}^{*}$ & 0.9 \\
\hline Haddock North Sea & $1963-2008$ & & & & & $\mathrm{nl}^{* *}$ & 2.2 \\
\hline Haddock VIa & $1978-2006$ & & & & & & 0.7 \\
\hline Herring Baltic 25-32 & $1974-2007$ & 1985 & $-0.58(0.18)^{* *}$ & & & $0.18(0.08)^{*}$ & -5.2 \\
\hline Herring Baltic 30 & $1973-2007$ & 1984 & $0.92(0.31)^{* *}$ & & & $0.6(0.18)^{* *}$ & -4.4 \\
\hline Herring Baltic Riga Bay & $1977-2007$ & & & & & $0.55(0.13)^{* *}$ & 2.3 \\
\hline Herring North Sea & $1960-2008$ & $1980^{*}$ & $0.55(0.15)^{* *}$ & & & $-0.73(0.14)^{* *}$ & -8 \\
\hline Herring Norweg. SS & $1921-2006$ & 1951 & $-0.99(0.31)^{* *}$ & & & $0.77(0.25)^{* *}$ & -5.8 \\
\hline Herring VIa & $1957-2007$ & & & & & $\mathrm{nl}^{* *}$ & 1 \\
\hline Plaice North Sea & $1957-2007$ & $1972^{*}$ & $0.59(0.14)^{* *}$ & & & $-0.38(0.12)^{* *}$ & -3.7 \\
\hline Plaice VIIa & $1964-2005$ & $1988^{* *}$ & $-0.57(0.08)^{* *}$ & & & & -22.7 \\
\hline Plaice VIId & $1980-2007$ & & & & & $\mathrm{nl}^{*}$ & 3.8 \\
\hline Plaice VIIe & $1976-2006$ & 1994 & $0.6(0.25)^{*}$ & & & $-0.96(0.25)^{* *}$ & -0.8 \\
\hline Saithe Faroe & 1961-2005 & 1980 & $0.44(0.19)^{*}$ & & & $0.59(0.27)^{*}$ & -0.8 \\
\hline Saithe Iceland & $1974-2007$ & 1987 & $-0.51(0.19)^{*}$ & & $0.59(0.33)$ & & -2.4 \\
\hline Saithe $3 a 46$ & $1967-2005$ & 1984 & $-0.61(0.23)^{*}$ & $0.74(0.36)^{*}$ & & & -1.1 \\
\hline Saithe Northeast Arctic & $1960-2005$ & $1988^{*}$ & $0.6(0.14)^{* *}$ & & & & -8.8 \\
\hline Sole North Sea & $1957-2007$ & & & & & & 1 \\
\hline Sole VIIa & 1970-2004 & $1990^{* *}$ & $-1.18(0.3)^{* *}$ & $0.85(0.36)^{*}$ & & & -12.9 \\
\hline Sole VIIe & 1969-2006 & & & & & $\mathrm{nl}^{*}$ & 2.1 \\
\hline Sole VIIfg & $1971-2006$ & & & & & $0.25(0.13)$ & $\begin{array}{l}2.1 \\
2.6\end{array}$ \\
\hline Whiting VIIek & $1982-2007$ & 1990 & $0.59(0.27)^{*}$ & & & $-0.81(0.27)^{* *}$ & -0.2 \\
\hline
\end{tabular}

catchability over time and the effects of aging errors. However, the quality of the data used in the present paper is the best available for the stocks studied and the relatively long period covered and, since the North Atlantic is a data-rich area, is likely better than for stocks from most other areas.

MA was calculated for each stock and year separately as the spawner biomass-weighted average across all age classes:

$$
\mathrm{MA}_{t}=\frac{\sum_{a=a_{\min }}^{a=a_{\max }} a M_{a, t} N_{a, t} W_{a, t}}{\sum_{a=a_{\min }}^{a=a_{\max }} M_{a, t} N_{a, t} W_{a, t}}
$$

where $a_{\min }$ and $a_{\max }$ are the ages of the youngest and the oldest of the spawners in year $t$, respectively, and $M_{a, t}, N_{a, t}$ and $W_{a, t}$ are the proportion of mature fish, the number of fish, and the mean weight of fish, respectively, at age $a$ and time $t$. 


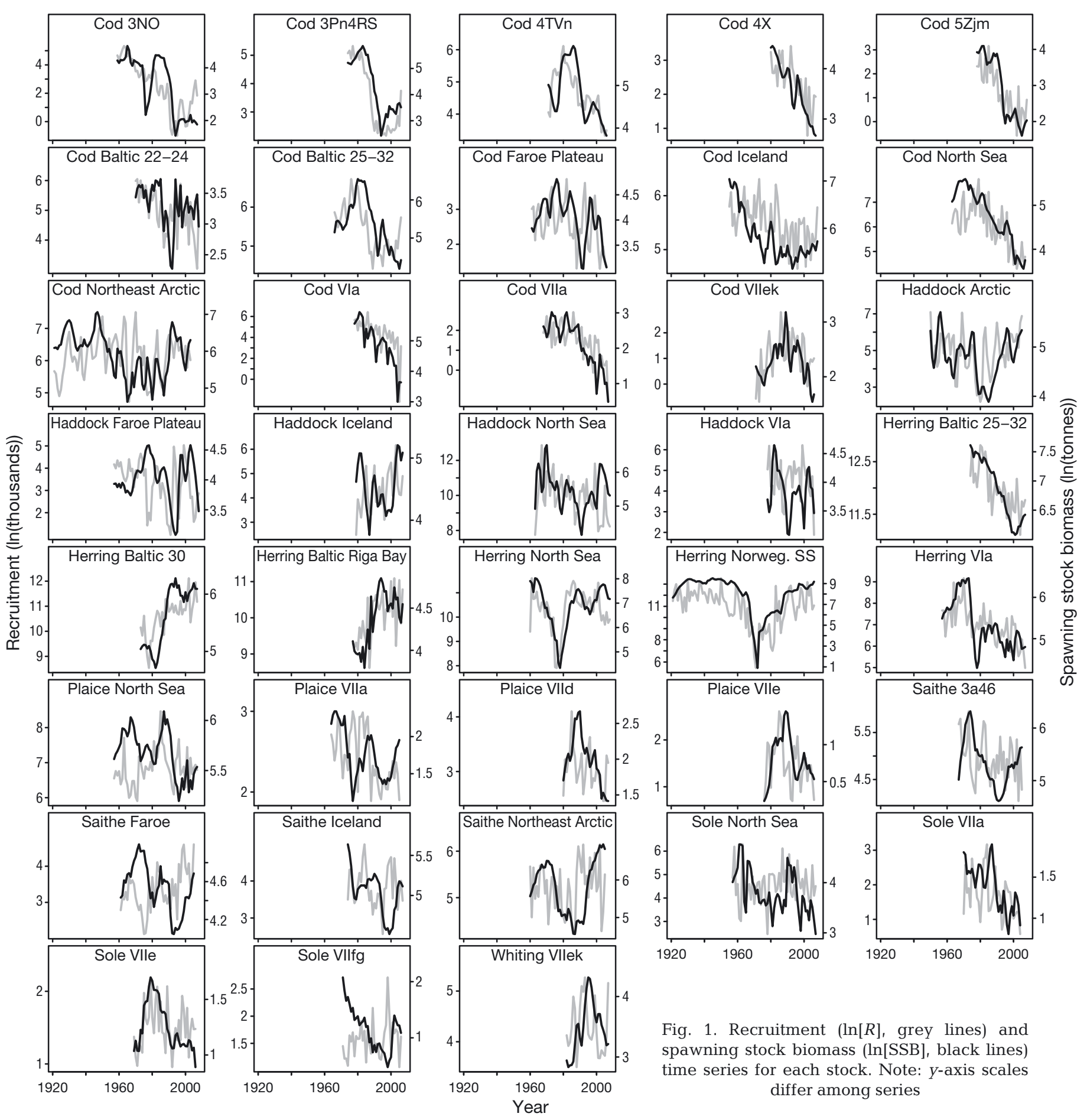

Time series of MA for each of the stocks are presented in the form of $15 \mathrm{yr}$ moving averages centred on the mean year. The averaging was done to smooth over the variation caused by the influence of particularly strong cohorts. This is for visualisation purposes only; the smoothed values were not used in any calculations.

\section{Temperature data}

We compiled area-specific sea temperature data series ( $\mathrm{T}$ ) based on several sources, according to availability. For the 4 Barents Sea stocks (cod, haddock Melanogrammus aeglefinus, herring Clupea harengus, and saithe Pollachius virens; Table 1), 
temperature data were obtained from the Kola meridian transect $\left(33^{\circ} 30^{\prime} \mathrm{E}, 70^{\circ} 30^{\prime}\right.$ to $\left.72^{\circ} 30^{\prime} \mathrm{N}\right)$. The monthly values made available to us were calculated by averaging temperatures horizontally along the transect and vertically from 0 to $200 \mathrm{~m}$ water depth (Bochkov 1982, Tereshchenko 1996), with recent data kindly made available by PINRO, Murmansk (www.pinro.ru). Yearly winter values were calculated by averaging over the months of December to March as in Ottersen et al. (2006).

For each of the remaining NE Atlantic stocks, time series of sea surface temperature (SST) were averaged annually and over the statistical areas defined by ICES to correspond to the distribution area of the respective stock. Data were extracted from the extended reconstructed SST (NOAA_ERSST_V3) data set based on the International Comprehensive OceanAtmosphere Data Set (ICOADS) SST data and provided by the NOAA/OAR/ESRL PSD, Boulder, CO, USA, at www.esrl.noaa.gov/psd/data/gridded/data. coads.2deg.html (accessed 12 August 2011). These data are available from 1880 to 2009 with $2^{\circ} \times 2^{\circ}$ grid resolution.

For NW Atlantic cod stocks, temperature values were allocated as follows:

- 3NO: ICOADS SST values (i.e. source as above)

- 3Pn4RS and 4TVn: annual temperature averages at $150 \mathrm{~m}$ depth for the Gulf of St. Lawrence from www.meds-sdmm.dfo-mpo.gc.ca/isdm-gdsi/azmppmza/climat/stlawrence/depth-profondeur-eng.htm (Galbraith et al. 2009)

- 4X and 5Zjn: annual averages of monthly SST values from www.meds-sdmm.dfo-mpo.gc.ca/isdmgdsi/azmp-pmza/climat/sst-tsm/costal-cotieres-eng. asp?id=Halifax (missing values replaced by the longterm monthly mean for 1926 to 2009 before averaging).

\section{Statistical analyses}

Stability of temperature-recruitment correlations

As an initial, visual inspection of how the strength of temperature-recruitment correlations changed with time, we conducted a moving-windows correlation analysis applying a $15 \mathrm{yr}$ time window. That is, we sliced the time-range into overlapping time-slots of $15 \mathrm{yr}$ and for each time-slot computed the correlation between the temperature in the spawning year and the natural logarithm of the number of recruits lagged so that the year corresponds to the spawning year. The resulting series of correlation coefficients were plotted against the mid-year of the time-slots.
As for MA, the averaging was done for visualisation purposes only; the smoothed values were not used in any calculations.

\section{Recruitment models}

We then fitted statistical recruitment models to each time series. We first considered stationary models with no effect of temperature, a linear effect of temperature, or a nonlinear effect of temperature on recruitment success. The nonlinear model was included because a nonlinear effect of temperature could hypothetically lead to apparent non-stationarity in the linear effect if the mean temperature changed over time. We then considered non-stationary model formulations, in which the recruitment success or the effect of temperature changed over time, either gradually (linearly) or stepwise. The different models were compared in a uniform approach, using Akaike's information criterion (Akaike 1974) corrected for small sample size $\left(\mathrm{AIC}_{\mathrm{C} i}\right.$ Hurvich \& Tsai 1989) as the model selection criterion.

\section{Baseline recruitment model}

The recruitment dynamics were analysed using regression models with the natural logarithm of the ratio between the number of recruits $\left(R_{t+a}\right)$ and spawning stock biomass $\left(\mathrm{SSB}_{t}\right)$ as the response variable. The subscript $a$ is the recruitment age (which varied among stocks), such that $R_{t+a}$ represents the recruitment back-lagged to the spawning year. According to the Ricker model (Ricker 1954), this logratio is a linear function of $\mathrm{SSB}_{t}$ :

$$
\ln \left(R_{t+a} / \mathrm{SSB}_{t}\right)=\mathrm{a}+\mathrm{bSSB}_{t}+\varepsilon_{t}
$$

This linear regression formulation of the Ricker model was fitted by maximum likelihood methods assuming normally distributed errors $\left(\varepsilon_{t}\right)$.

As a simple test of the suitability of applying Rickertype models, we examined plots of $\ln \left(R_{t+a} / \mathrm{SSB}_{t}\right)$ against SSB (Appendix 1). A linear relationship, as implied by Eq. (1), seemed to fit the data relatively well; there were no obvious systematic deviations that might, for example, have indicated Allee effects (disproportionally low recruitment success at very low SSB). Additional modelling, analysing log-recruitment as a smooth function of SSB, showed that the main results reported in the present paper were not strongly sensitive to the choice of a particular stock-recruitment model (results not shown). 


\section{Linear temperature-effect model}

To introduce temperature effects on the stockrecruitment relationship and thus allow for exploration of H1, we extended Ricker's model (Eq. 1) by separating the density-independent effect into a global intercept and a linear temperature-dependent effect $\left(T_{t}\right.$, scaled to zero mean) on pre-recruit survival:

$$
\ln \left(R_{t+a} / \mathrm{SSB}_{t}\right)=\mathrm{a}+\mathrm{bSSB}_{t}+\mathrm{c} T_{t}+\varepsilon_{t}
$$

Note that if $\mathrm{SSB}_{t}$ scales with the egg production, $\ln \left(R_{t+a} / \mathrm{SSB}_{t}\right)$ is a linear function of the instantaneous pre-recruit survival rate (i.e. $1-M$ in $N_{t}=N_{0} \mathrm{e}^{-M t}$, where $N_{t}$ is cohort size at time $t$ ). Linear terms in the right-hand side of the equation therefore represent linear effects on survival rate.

\section{Nonlinear temperature effects}

To explore if temperature had nonlinear effects on pre-recruit survival, we compared Model 2 to a model with a smooth temperature effect:

$$
\ln \left(R_{t+a} / \mathrm{SSB}_{t}\right)=\mathrm{a}+\mathrm{bSSB}_{t}+f\left(T_{t}\right)+\varepsilon_{t}
$$

Here, $f\left(T_{t}\right)$ is a natural cubic spline function with maximally 2 degrees of freedom ( 3 knots). Model 3 is a generalized additive model (GAM) and was fitted by maximum-likelihood methods using the mgcv package (Wood 2006) in the R program development environment (R Development Core Team 2010). The AICc values of Models 1, 2 and 3 were compared, and the model formulation that provided the lowest $\mathrm{AIC}_{\mathrm{C}}$ value was selected as the most parsimonious stationary model.

Non-stationarity in recruitment dynamics: testing for gradual changes

To examine if the relationship between spawning stock biomass, recruitment, and temperature changed over time (i.e. that the recruitment model was nonstationary, H2), we first considered 2 linear extensions of Model 2:

$\ln \left(R_{t+a} / \mathrm{SSB}_{t}\right)=\mathrm{a}+\mathrm{bSSB}_{t}+\mathrm{c} T_{t}+\mathrm{d} y r_{t}+\varepsilon_{t}$

$\ln \left(R_{t+a} / \mathrm{SSB}_{t}\right)=\mathrm{a}+\mathrm{bSSB}_{t}+\mathrm{c} T_{t}+\mathrm{d} y r_{t}+\mathrm{eyr}_{t} T_{t}+\varepsilon_{t}$

With Model 4, we tested for a linear effect of year $(y r)$, that is, for a trend in the intercept; with Model 5 we tested for an interaction effect between year and temperature, that is, for a trend in the effect of tem- perature. When searching for the most parsimonious non-stationary linear model, we also calculated the $\mathrm{AIC}_{\mathrm{C}}$ of a reduced version of Model 4, with the temperature term omitted.

\section{Stepwise shifts in recruitment dynamics}

The subsequent analysis focused on non-stationary models testing for a stepwise change in the recruitment dynamics. That is, instead of assuming linear changes in the intercept or temperature effect as in Models 4 and 5, the intercept and potentially the coefficient for the temperature effect were assumed to change abruptly at some time-point for each stock.

When a statistically significant shift in recruitment dynamics was detected, we followed up by assessing which other variables changed for that stock, to evaluate the hypotheses $\mathrm{H} 3$ to $\mathrm{H} 7$.

We considered the following threshold models:

$$
\begin{aligned}
& \ln \left(R_{t+a} / \mathrm{SSB}_{t}\right)= \\
& \mathrm{a}_{0} I_{A, t}+\mathrm{a}_{1} I_{B, t}+\mathrm{bSSB}_{t}+\varepsilon_{t} \\
& \ln \left(R_{t+a} / \mathrm{SSB}_{t}\right)= \\
& \mathrm{a}_{0} I_{A, t}+\mathrm{a}_{1} I_{B, t}+\mathrm{bSSB}_{t}+\mathrm{c} T_{t}+\varepsilon_{t} \\
& \ln \left(R_{t+a} / \mathrm{SSB}_{t}\right)= \\
& \mathrm{a}_{0} I_{A, t}+\mathrm{a}_{1} I_{B, t}+\mathrm{bSSB}_{t}+\mathrm{C}_{0} T_{t} I_{A, t}+\varepsilon_{t} \\
& \ln \left(R_{t+a} / \mathrm{SSB}_{t}\right)= \\
& \mathrm{a}_{0} I_{A, t}+\mathrm{a}_{1} I_{B, t}+\mathrm{bSSB}_{t}+\mathrm{c}_{1} T_{t} I_{B, t}+\varepsilon_{t} \\
& \ln \left(R_{t+a} / \mathrm{SSB}_{t}\right)= \\
& \mathrm{a}_{0} I_{A, t}+\mathrm{a}_{1} I_{B, t}+\mathrm{bSSB}_{t}+\mathrm{C}_{0} T_{t} I_{A, t}+\mathrm{c}_{1} T_{t} I_{B, t}+\varepsilon_{t}
\end{aligned}
$$

Here, $I_{A}$ and $I_{B}$ are indicator variables separating the time-series into 2 periods, $\mathrm{A}$ and $\mathrm{B}$, with $I_{A, t}=1$ and $I_{B, t}=0$ for Period A, while $I_{A, t}=0$ and $I_{B, t}=1$ for Period B. For any given threshold year separating Period A from Period B, Models 6a to 6e are linear and were estimated by maximum-likelihood methods assuming normally distributed errors. The optimal threshold year for any given stock and model formulation was found by comparing the $\mathrm{AIC}_{\mathrm{C}}$ of alternative threshold years and selecting the threshold providing the lowest $\mathrm{AIC}_{\mathrm{C}}$.

Model 6a (Eq. 6a) modifies the Ricker model (Eq. 1) in that the intercept is different between 2 time periods. Model 6b is similar to Model 6a but includes a temperature effect. In Model 6c, temperature only has an effect in the first period (Period A), and in Model 6d, only in the second period (Period B). In Model 6e, temperature has an effect in both periods, but the strength (and possibly sign) of the temperature effect differs between the periods. Note that 
Model 6e is the most general model and that Models 1,2 and 6 a to 6 e can be seen as special cases (with $\mathrm{a}_{0}$ $=\mathrm{a}_{1}, \mathrm{c}_{0}=\mathrm{C}_{1}, \mathrm{c}_{0}=0$ and/or $\mathrm{c}_{1}=0$ ). The optimal threshold model formulation was found by comparing the $\mathrm{AIC}_{\mathrm{C}}$ of Models $6 \mathrm{a}$ to $6 \mathrm{e}$.

If the $\mathrm{AIC}_{\mathrm{C}}$ of the best threshold model (Models 6a to 6e) was lower than that of the best stationary model (Models 1 to 3), we then went on to calculate the statistical significance of the threshold. The statistical significance of the threshold was calculated for the full model (Eq. 6e) using a permutation test as described by Liu et al. (2011). To calculate the $\mathrm{AIC}_{\mathrm{C}}$ of threshold models, the threshold value was arbitrarily counted as 1 parameter.

\section{Testing hypotheses for temporal shifts in recruitment dynamics}

For each of the stocks with an identified shift in recruitment dynamics, we calculated the change from Period A to B in the intercept and in the effect of temperature on recruitment success. To evaluate the hypotheses relating to the temporal shifts in recruitment dynamics, we conducted statistical tests regarding whether these changes were associated with changes in MA, SSB, and temperature, tested individually (Table 3). Specifically, we fitted linear regression models with stock as the sampling unit, the change in the intercept or the change in temperature effect as the response variable, and the change in $\mathrm{MA}, \mathrm{SSB}$, and temperature as predictor variables.

Table 3. Test of hypotheses exploring if a shift in recruitment dynamics (non-stationarity) is explainable through changes in mean age in the spawning stock (MA), spawning stock biomass (SSB) or temperature. Change in intercept: $\mathrm{a}_{1}-\mathrm{a}_{0}$ in Eq. (6). Change in temperature effect: change in the estimated effect of temperature on recruitment success, $\mathrm{C}_{1}-\mathrm{C}_{0}$ in Eq. (6)

\begin{tabular}{|ll|}
\hline Hypothesis & \multicolumn{1}{c|}{ Prediction } \\
\hline H3 & $\begin{array}{c}\text { Change in intercept correlates positively to } \\
\text { the concurrent change in MA } \\
\text { Change in intercept correlates positively to } \\
\text { the concurrent change in SSB } \\
\text { Change in intercept correlates to the } \\
\text { H5 }\end{array}$ \\
H6 & $\begin{array}{c}\text { Change in absolute value of temperature } \\
\text { effect correlates negatively to the } \\
\text { concurrent change in MA }\end{array}$ \\
Change in absolute value of temperature \\
effect correlates negatively to the \\
\end{tabular}

\section{RESULTS}

\section{Effect of temperature on recruitment success (H1)}

To address the impact of temperature on the stockrecruitment relationship, (1) linear temperature terms were added to simple Ricker models of the relationship between recruitment success $(\ln [R / \mathrm{SSB}])$ and SSB. Of the 38 stocks, 18 showed temperature effects statistically significant at the 5\% level, with 9 negative and 9 positive (Table 1). (2) GAMs were used. Adding possibly nonlinear (smooth) terms of temperature to the Ricker models within the GAM framework led to the identification of statistically significant temperature effects for an additional 3 stocks (Table 1).

The most interesting result at the species level is for herring. All 6 herring stocks displayed significant temperature effects. The cold-water stocks (Norwegian spring-spawning and the 3 from the Baltic) showed a positive response to higher temperatures, while the North Sea and West of Scotland stocks responded negatively (Table 1). Note that none of the $5 \mathrm{NW}$ Atlantic cod stocks studied displayed a statistically significant temperature effect.

\section{Temporal development of temperature-recruitment correlations (H2)}

For each stock, the temporal development of the temperature-recruitment correlations was inspected by calculating moving $15 \mathrm{yr}$ window correlations. The correlations between temperature and recruitment have for many stocks changed considerably over time (Fig. 2). For example, for the populations of cod, herring, haddock and saithe in the Barents Sea region, there were increasingly strong positive correlations from around the 1960s onwards, which weakened in the 1990s to 2000s. In contrast, in the North Sea there is a pattern of increasingly negative correlations for several stocks.

\section{Temporal development of MA and possible link to temperature-recruitment correlations (background for $\mathrm{H3}$ and $\mathrm{H6}$ )}

No general pattern was found. For some stocks, notably the Northeast Arctic and Icelandic cod, plaice Pleuronectes platessa in the North Sea, and sole Solea solea in the North Sea, Celtic Sea 


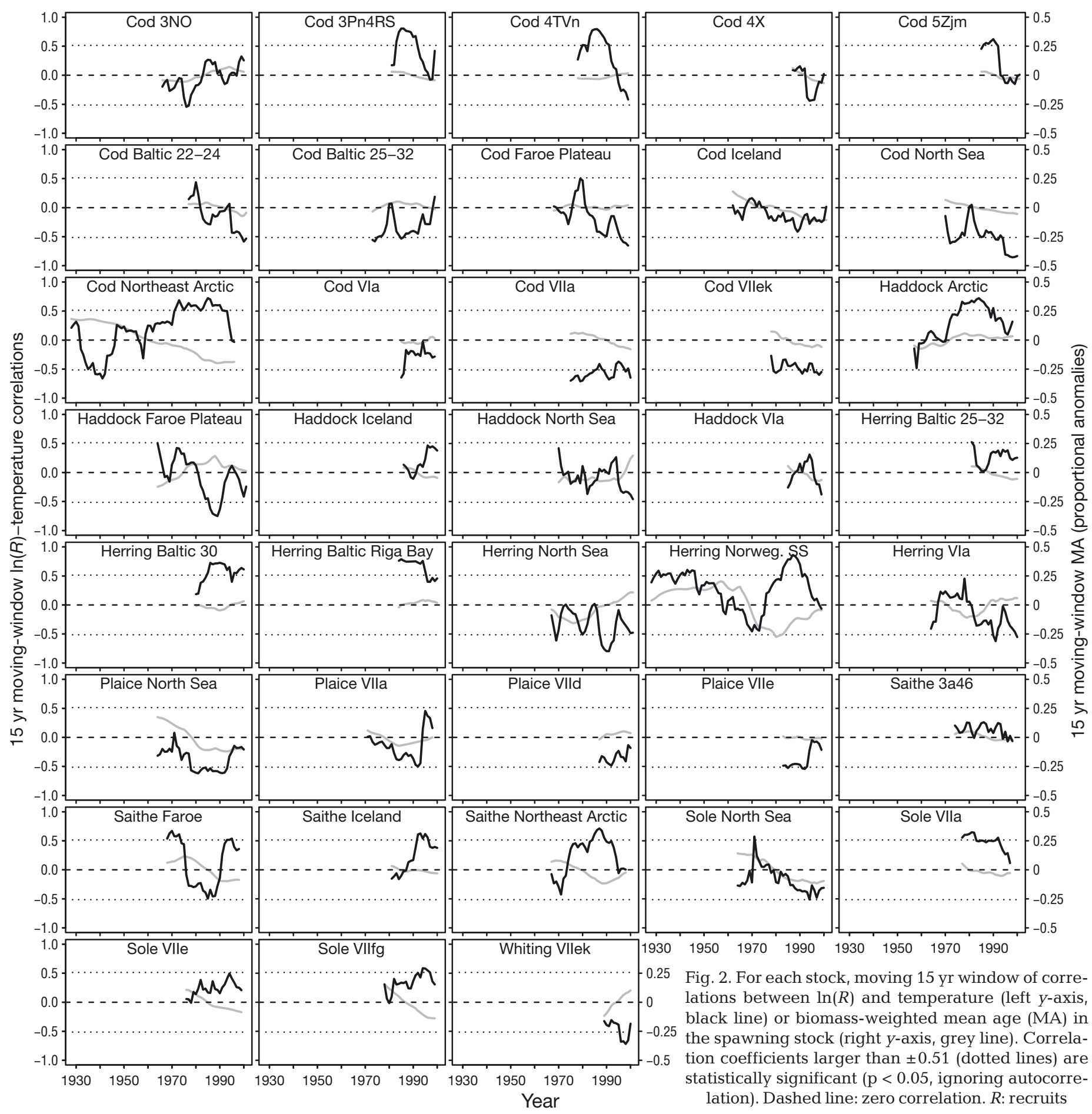

(VIIfg), and Western English Channel (VIIe), there was a clear decrease in MA (Fig. 2). In contrast, other stocks showed very little change in MA, e.g. Icelandic saithe, Faeroe Plateau and Baltic cod, and herring in the Baltic and Gulf of Riga. Further, some stocks displayed an increase in MA, either over the full period (Southern Grand Banks [3NO] cod) or the recent decades (Norwegian springspawning, North Sea, and West of Scotland herring; Fig. 2).

Further, for some stocks, such as the Northeast Arctic cod, the Norwegian spring-spawning herring, and the Northeast Arctic saithe, a general reduction in MA was accompanied by an increase in the tem- 
perature-recruitment correlation. The pattern is far from universal, however. For example, reduced MA did not coincide with increased temperature-recruitment correlations of the Arctic haddock or the Faroe Islands cod stocks (Fig. 2).

\section{Detecting temporal shifts in recruitment dynamics (H2)}

When comparing stationary (Eqs. 1-3) and nonstationary linear (Eqs. 4 \& 5) models of recruitment dynamics, we found that 14 stocks showed statistically significant $(p<0.05)$ linear changes in the intercept over time, and 4 stocks statistically significant linear changes in the effect of temperature (Table 1). These stocks largely coincided with the 13 stocks showing statistically significant stepwise changes (Eq. 6), as confirmed by a statistically significant $(p<0.05)$ threshold in recruitment dynamics (Table 2). For an additional 14 stocks, threshold models provided lower (approximate) AICc compared to the best linear or nonlinear stationary models (Eqs. 1-3), but the threshold was not statistically significant. For 12 of the 13 stocks with a statistically significant threshold, the AICc was also lower for the threshold models (Table 2) compared to the non-stationary linear models (Table 1). Note that these $\mathrm{p}$-values do not account for multiple testing and that we expect that $\sim 2$ stocks would show statistically significant results at $\mathrm{p}<0.05$ just by chance. If we use a more conservative critical value of 0.01 , we expect that $\sim 0.4$ stocks would show statistically significant results just by chance. Eight stocks showed shifts in recruitment dynamics that were statistically significant at $\mathrm{p}<0.01$ (Table 2). Among the 13 stocks with a significant threshold $(p<0.05)$, all showed significant changes in the intercept; 5 of these also showed changes in the effect of temperature.

\section{Examining possible causes of temporal shifts in recruitment dynamics ( $\mathrm{H3}, \mathrm{H} 4$, and $\mathrm{H5}$ )}

All further analyses focused on the 13 stocks with a temporal (threshold) shift in recruitment dynamics (as shown in Fig. 3 and Table 2). Fig. 4 shows the change from the first to the second period in the intercept for each stock in response to the change in SSB, MA, and temperature. We see a clear positive effect of SSB and a negative effect of MA (both $\mathrm{p}<0.01$ when added into 1 regression model) that together explain $77 \%$ of the variation among stocks. Stocks that declined in SSB from the first to the second period produced less recruits after the shift than expected from a Ricker model fitted to the whole time series, while stocks that increased in SSB showed an increase in recruitment success. To further investigate the possible causal relationship between the changes in recruitment success and SSB, we tested what changed first. By fitting threshold models for a stepwise change in SSB over time for each of the 13 stocks, we found that the change in recruitment success generally preceded the change in spawning stock biomass. Specifically, for 10 stocks, the major change in SSB occurred 5 to $21 \mathrm{yr}$ after the estimated shifts in recruitment dynamics. The changes in recruitment success were not statistically significantly linked to concurrent changes in sea temperature (Fig. 4).

\section{Examining the temperature-recruitment relationship (H6 and H7)}

The next step was to explore how the strength of the temperature effect changed between the periods for the 8 stocks with a temporal shift in recruitment dynamics and a statistically significant effect of temperature in at least 1 of the 2 periods (Table 2, Fig. 3). Specifically, we explored how this change corresponded to the changes in SSB and MA. We a priori predicted that lower SSB and lower MA would lead to stronger recruitmenttemperature correlation (in terms of the absolute value). However, the changes in the strength of the temperature effect were not statistically significantly linked to either the changes in SSB or MA (Fig. 5). The results did not change qualitatively if we included in the analysis stocks with weaker statistical support for the threshold dynamics (lower $\mathrm{AIC}_{\mathrm{C}}$ than stationary models but nonsignificant threshold; points outlined in grey in Figs. 4 \& 5).

\section{DISCUSSION}

The discussion of our results in the context of earlier related work is focused around and structured according to the hypotheses formulated in the 'Introduction'. 


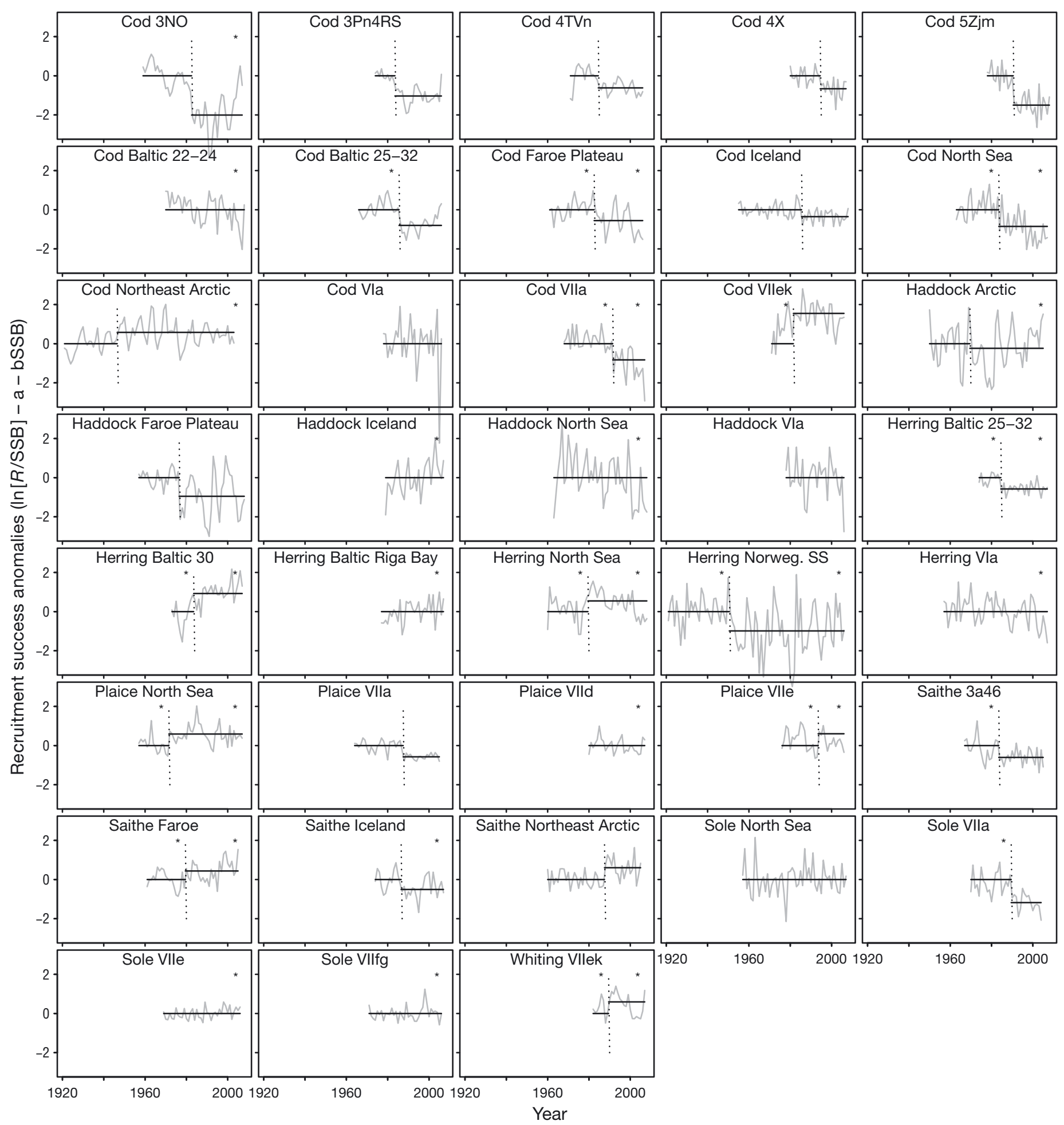

Fig. 3. Temporal shifts in recruitment dynamics. Grey lines show time series of recruitment success anomalies $(=\ln [R / \mathrm{SSB}]-$ $\mathrm{a}-\mathrm{bSSB}$, where $\mathrm{a}$ and $\mathrm{b}$ are regression coefficients from Ricker-based models potentially also including effects of climate and recruitment shifts, $R$ is number of recruits, and SSB is spawning stock biomass). Horizontal lines show how predicted recruitment success at a given SSB and mean temperature changes over time. Vertical dotted lines: shifts in recruitment dynamics. Asterisks indicate that the selected model included an effect of temperature for the given period 

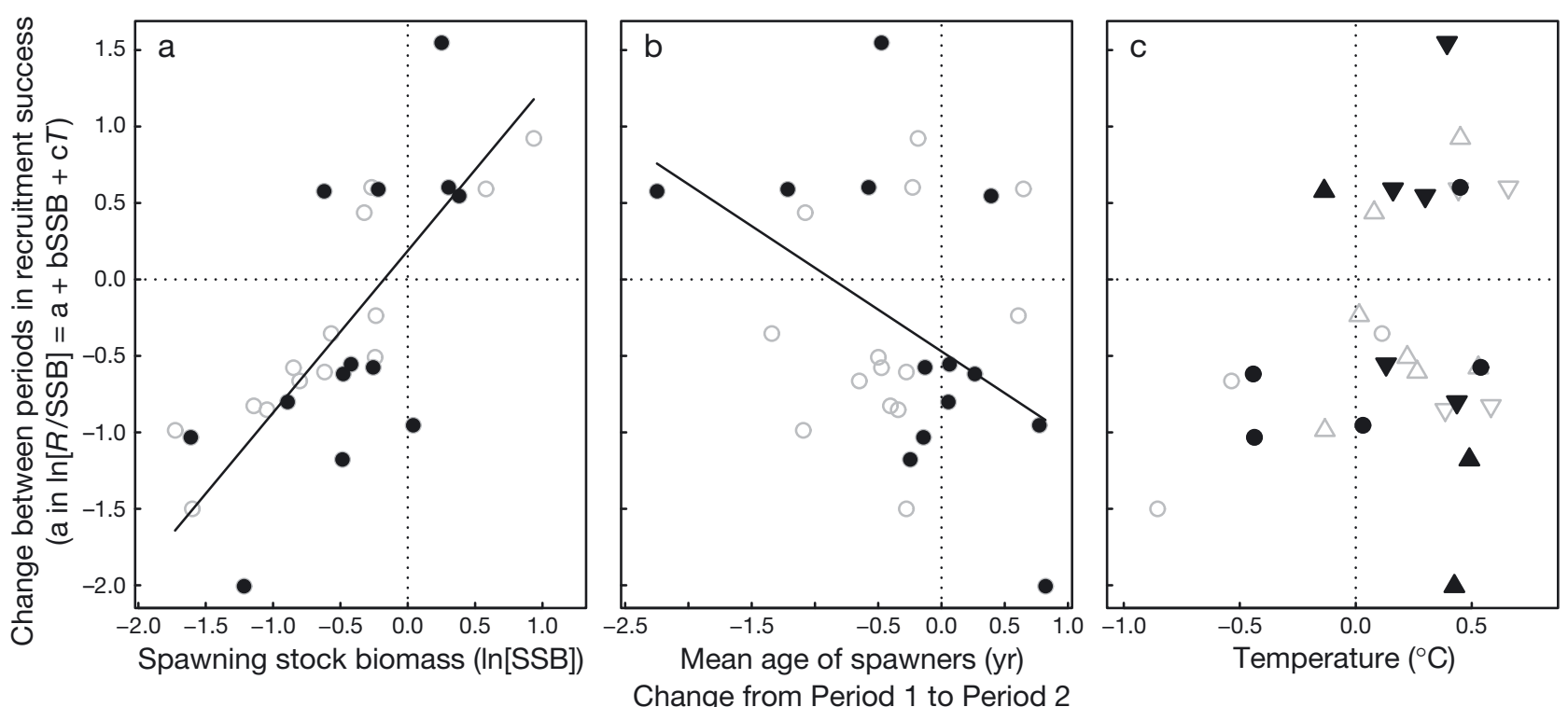

Fig. 4. Temporal change in predicted recruitment success for 27 stocks with an estimated shift in recruitment dynamics in response to the concurrent changes in factors potentially linked to these shifts. Filled, black symbols: shift in recruitment dynamics statistically significant ( $\mathrm{p}<0.05, \mathrm{~N}=13$ stocks). Open, grey symbols: shift not statistically significant, but threshold-model has lower $\operatorname{AIC}_{C}(\mathrm{~N}=14)$. The $y$-variable is the change in the predicted number of recruits $(R)$ per biomass of spawners $(\ln [R / \mathrm{SSB}])$ at a given spawning stock biomass (SSB) and temperature from the first to the second period (= difference between horizontal lines in Fig. 3). The $x$-variables are the concurrent changes between the periods in (a) spawning stock biomass, (b) mean age of the spawners, and (c) temperature. Lines: regression lines for across-stock comparison of the change in recruitment success in response to the change in SSB and MA combined (both $\mathrm{p}<0.01, \mathrm{R}^{2}=0.77, \mathrm{n}=13$ stocks with statistically significant shifts). Symbols in (c) represent sign of average estimated temperature effect for the 2 periods for each stock (upward-pointing triangles: positive; downward-pointing: negative; circles: none)
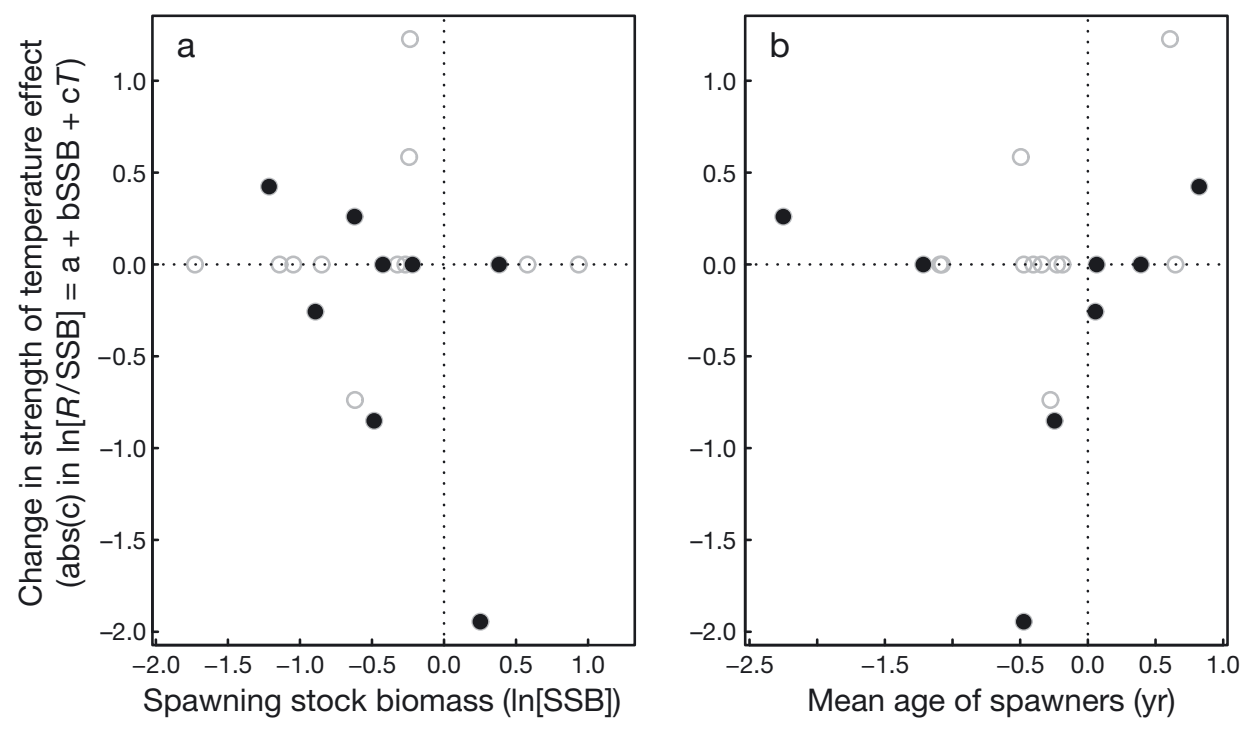

Change from Period 1 to Period 2

Fig. 5. Temporal change in strength of the temperature effect on recruitment success as a function of the concurrent changes in (a) spawning stock biomass (SSB) and (b) mean age. The $y$-variable is the change in the absolute value of the estimated temperature effect for each of 8 stocks with a significant shift in recruitment dynamics and a statistically significant effect of temperature in at least 1 of the 2 periods (Fig. 3). Open, grey symbols: shift not statistically significant, but threshold-model has lower $\mathrm{AIC}_{\mathrm{C}}(\mathrm{N}=12)$. $R$ : number of recruits 


\section{The stock-recruitment relationship is enhanced by including a temperature term (H1)}

Our results support earlier work in that temperature is an important factor for some of the stocks and provide suggestive evidence for several general patterns (Table 1). For instance, the effect of temperature on recruitment was positive for cold-water herring stocks and negative for stocks in the more temperate southern areas. It is likely no coincidence that we found a temperature signal for this species as small pelagic fish, like herring, are well-known to respond to climate fluctuations (Checkley et al. 2009).

That the sign of the relationship can vary between stocks of the same species is also as expected, and it is intuitively sensible that populations that inhabit the coldest water within a species' temperature range tend to show increasing recruitment with increasing temperatures, whereas those inhabiting the warmest waters show decreasing recruitment with increasing temperatures. This pattern has earlier been shown to apply to the main Atlantic cod stocks (Planque \& Fredou 1999) but to our knowledge not for herring.

For plaice, only 4 stocks from around the British Isles were analysed. For all of these stocks, located towards the centre of the overall distribution range of plaice, a tendency toward recruitment being favoured by lower temperatures was found. (Table 1). This is consistent with what has earlier been documented by Fox et al. (2000), who further pointed to temperature during the first months of the year being of particular importance by affecting predation pressure on the planktonic stages of plaice and subsequently their recruitment. There are unfortunately not sufficient data to examine the temperature effects on the populations of this species with a more southern distribution (e.g. Bay of Biscay and around the Iberian peninsula).

Our results for cod were less clear (Table 1). A negative temperature effect was, as expected from the above, found for the North Sea and Irish Sea stocks. However, no statistically significant effect was found for any of the Northwest Atlantic stocks. This may partly be explained by these time series being relatively short, but there may have been other changes in these stocks which overshadow the temperature impact and which we are not able to capture. It is more surprising that no statistically significant effect was detected for the Barents Sea cod. Several earlier papers have pointed to temperature being a particularly important driver for the recruitment to this most northerly cod stock (e.g. Sætersdal \& Loeng 1987,
Ottersen \& Stenseth 2001), and Myers (1998) singled out this as one of the few stocks where the temperature-recruitment relationship was stable over time. Nevertheless, Fig. 2 shows clearly, as was demonstrated by Ottersen (2008), that the correlation is nonstationary, negative in some periods, positive in others, and with an increasing trend from around 1940 to 1990 followed by a distinct drop-off. This was supported by our statistical analysis, showing a significant shift in recruitment dynamics around 1947, with higher recruitment from 1947 onward compared to 1921 to 1946 . Further recruitment was positively (although not statistically significantly) related to temperature only from 1947 onward.

To sum up, of the 21 stocks for which adding a smooth temperature term statistically significantly improved the Ricker model, linear temperature effects were favoured in terms of $\mathrm{AIC}_{\mathrm{C}}$ for 11 stocks and nonlinear effects for 10 stocks (Table 1). The frequent occurrence of non-linearity is of importance since many studies, including earlier work by the present first author, examined linear or possibly log-linear environment-relationships only, typically through correlation or linear regression (Loeng et al. 1995, Ottersen et al. 2002). Moreover, such nonlinear effects can lead to changes in the linear relationship between temperature and recruitment.

\section{The relationship between recruitment, spawning stock biomass, and temperature is not constant over time (H2)}

As expected, but now further documented by systematic analyses, H2 is valid. The most frequent change in the non-stationary linear models was, for 14 stocks, in the intercept in recruitment success, suggesting a change in pre-recruit mortality over time. Furthermore, a statistically significant threshold in recruitment dynamics (Eq. 6) was found for 13 stocks; for an additional 14 stocks (making 27 of the total of 38 stocks), threshold models performed better than the best linear or nonlinear stationary models (Eqs. 1-3) in terms of $\mathrm{AIC}_{\mathrm{C}}$, but the threshold was not statistically significant. The good performance of threshold models, while not providing evidence for ecological regime shifts, does suggest that abrupt changes frequently take place. While no overall geographic pattern was found, some neighbouring stocks showed similar patterns. Most noteworthy is the statistically significant shift in 3 NW Atlantic cod stocks in 1983 to 1985 , in all cases with a clear threshold (Table 2). 
Changes in the relationship between temperature and recruitment were shown by the moving-window correlations (Fig. 2) and quantified by the nonstationary modelling. These analyses revealed significant linear changes in the effect of temperature for only 4 stocks (Table 1) and stepwise changes for 8 stocks (Table 2). In most cases with a change in recruitment dynamics, the best model had a common temperature effect for the whole period (Tables 1 \& 2).

There are several reasons why the temperaturerecruitment links examined might change over time. First, temperature effects may for some stocks be marginal compared to those of other environmental factors. We were, for instance, unable to detect a statistically significant temperature-recruitment relationship for cod in the Baltic Sea for the whole period studied (Table 1). For this brackish sea, there is substantial literature indicating that reproduction of cod is heavily dependent on the right salinity and oxygen conditions (e.g. Köster et al. 2005, Hinrichsen et al. 2011). If the correlation between salinity, oxygen, and temperature changes over time, this could then lead to a changed temperature-recruitment relationship. In our study, we found that temperature contributed to predict cod recruitment in the Baltic Sea proper prior to 1987, while from 1987 onward, the recruitment was drastically reduced and unlinked to temperature. This shift coincided with large-scale changes in both abiotic and biotic conditions in the Baltic Sea between 1988 and 1993, including reductions in salinity and oxygen and increased abundance of sprat Sprattus sprattus, predators on cod eggs (Möllmann et al. 2009).

Second, the effect of temperature may depend on ecosystem state. Temperature may affect fish stocks through complex pathways in the foodweb, where several direct and indirect mechanisms come into play. The importance to recruitment of the different mechanisms may change over time, as a mortality factor operating at an early life stage may or may not be overshadowed by mortality factors operating at later life stages. Mueter et al. (2007) emphasized that recruitment can be affected by predation; therefore, 'environmental' effects on productivity include changes in abundance of important predators, regardless of whether these were caused by environmental variability, fishing, or other factors. For instance, Stige et al. (2013, this volume) found changing relevance of different environmental factors (including sea temperature and abundance of cod age 3 to $6 \mathrm{yr}$ ) for predicting recruitment of the Northeast Arctic cod and the Northeast Arctic haddock in the Barents Sea. Further, variability in cannibalism (e.g. driven by changes in the availability of preferred prey, which again may be connected to temperature) may affect natural mortality of juveniles. Consequently, the net effect of temperature changes may be different, even opposite, according to the status of main prey, competitor, or predator populations. This has recently been examined in several Northeast Atlantic ecosystems, notably the Baltic (Cardinale et al. 2009, Lindegren et al. 2010), the Barents Sea (Svendsen et al. 2007, Stige et al. 2010), and the North Sea (Kempf et al. 2010).

Third, the effects of large-scale climate dynamics, as represented by e.g. the NAO, on fish recruitment may change at multi-decadal time scales for at least 3 different reasons (Stige et al. 2006): (1) Changes in demographic factors may affect the sensitivity of cod recruitment to climate fluctuations. (2) Changes may be related to long-term alterations in how the biotic or abiotic environment affects the way interannual variability in a given environmental factor affects cod recruitment. (3) The effect of NAO fluctuations on local environmental variables may change with time. This again implies that the lack of persistency of environment-recruitment correlations (Drinkwater \& Myers 1987, Myers 1998) may reflect true biological or physical changes, rather than being mere statistical artefacts.

However, there is indeed a risk of such statistical artefacts. The breakdown of a correlation or explanatory power of a model may be a consequence of failure to capture the essential explanatory variables. This is not unlikely, as the statistical modelling is complicated by the explanatory variables not being statistically independent, the uncertainty in the data, and the limited number of years for which data are available for any given stock.

In the following, relating to stocks that were found to display a statistically significant temporal shift in recruitment dynamics, we discuss possible causes for these shifts, formulated as hypotheses H3, H4, and H5.

\section{Recruitment per SSB decreases with decreasing MA (H3)}

The concept that juvenation of the spawning stock is unfavourable is well established (Ponomarenko 1973, Berkeley et al. 2004, Planque et al. 2010), and there exists substantial support for this being biologically plausible (Kjesbu et al. 1996, Marteinsdottir \& Thorarinsson 1998). Contrary to this, our results do not support H3 but indicate reduction in recruitment success from Period 1 to 2 for stocks with an increase in MA, and vice-versa (Fig. 4). 
The result above is weakened by a marked reduction in MA being the case only for a minority of the stocks studied (Fig. 2); only a few showed a decrease of the MA of $>1$ yr of age from Period 1 to 2 (Fig. 4). This could also partly be due to most of the time series being rather short and hence to the fact that fisheries-induced juvenation is likely to have already occurred prior to the beginning of our time series.

It is hard to give a biologically sound explanation for our results. However, the number of populations and species for which the validity of H3 has actually been studied is fairly limited, and the results are mixed. Morgan et al. (2007) explored the effect of age composition on recruitment in 3 Atlantic cod populations and 1 of American plaice Hippoglossoides platessoides. No consistent relationship between age composition of the spawning stock and recruitment was found, and they concluded that further research is needed to explore how common the effect of age composition on recruitment actually is (Morgan et al. 2007). Similarly, Ottersen (2008) found no clear link between age structure and recruitment for the Northeast Arctic cod stock, despite a clear reduction in MA with time. It was suggested that strong recruitment compensation, i.e. increased juvenile survival rate due to reduced pre-recruitment competition, may be the reason for this stock seemingly being quite robust regarding spawner juvenation (Ottersen 2008). Actually, this stock, with its pronounced reduction in MA, is an outlier in our analysis and contributes in particular to the negative relationship between MA and change in recruitment success (Fig. 4).

Until recently, H3 had not been examined across stocks. Brunel (2010) investigated how common such effects are by applying meta-analysis to $39 \mathrm{NE}$ Atlantic fish stocks. He tested relationships between age structure (spawner mean age, age diversity, and proportion of recruit spawners) and recruitment. Although statistically significant effects were found for some stocks, and indeed for some species overall, meta-analyses combining the stock-level tests revealed that none of the effects were statistically significant across all stocks. Thus, neither Brunel (2010) nor we find convincing support for H3 being generally applicable.

\section{Recruitment per SSB decreases with long-term reduction in SSB (H4)}

Our results seem to give support for H4. Stocks that declined in SSB from the first to the second period produced less recruits after the shift than expected from a Ricker model fitted to the whole time series, while stocks that increased in SSB showed an increase in recruitment (Fig. 4). This may suggest that long-term changes in SSB were associated with changes in pre-recruit mortality.

However, additional analysis showed that the change in pre-recruit survival generally preceded the change in stock size, suggesting that the low stock size was a result of the high mortality rather than the opposite. Consequently, the 2 mechanisms suggested in the 'Introduction' (prey to predator feedback loop and loss of spatial and genetic structure) do not seem to be the underlying cause of the findings. Instead, these results suggest that longterm changes in stock size often are driven by longterm changes in pre-recruit mortality. The literature suggests numerous biotic and abiotic factors that potentially may cause such long-term changes in pre-recruit mortality (see Houde 2008 and references therein).

\section{Recruitment per SSB changes with long-term changes in temperature (H5)}

Our results did not show support for H5 (Fig. 4). This is somewhat unexpected and seems to contradict earlier work by e.g. Mueter et al. (2007), who pointed out that climate may induce persistent change in recruitment dynamics. Our results, in contrast, indicate that climate generally is not the main driver behind the long-term (as opposed to inter-annual) changes in juvenile survival or that the temperature measurements fail to capture the key climate changes. Either alternative is possible; in most ecosystems there has been high fishing pressure, which, probably in combination with climate drivers, has caused major changes in fish stock abundance (Planque et al. 2010), both for the species analysed and their predators and prey. Further, temperature effects may for some stocks be marginal compared to those of other environmental factors, such as food availability or predation pressure, which may or may not be linked to temperature.

The following relates to stocks that were found to display a statistically significant temporal shift in recruitment dynamics and an effect of temperature in at least 1 of the 2 periods. We discuss how the strength of the temperature effect changed between the periods and how this change corresponded to the changes in MA and SSB, respectively, as formulated in hypotheses $\mathrm{H} 6$ and $\mathrm{H} 7$. 


\section{The temperature-recruitment relationship strengthens with decreasing MA (H6)}

It has been suggested that recruitment to a fish stock is more susceptible to environmental fluctuations when the spawning stock age composition has been skewed toward younger ages, i.e. H6. However, in our multi-stock analysis, the changes in the strength of the temperature effect did not scale statistically significantly with the changes in body massweighted mean age of spawners (Fig. 5). This is comparable to the only other study we are aware of that deals with more than 1 or a few stocks (Brunel 2010). Brunel (2010), in his meta-analysis of 39 NE Atlantic fish stocks, also tested relationships between age structure (body mass weighted spawner mean age, age diversity, and proportion of recruit spawners) and recruitment sensitivity to temperature. Metaanalyses combining the stock-level tests revealed that the spawner mean-age influence on recruitment sensitivity to temperature was not statistically significant across all stocks.

\section{The temperature-recruitment relationship strengthens with decreasing SSB (H7)}

In our analyses, the changes in strength of the temperature effect on recruitment success did not show any statistically significant link to changes in SSB (Fig. 5). This is in concordance with the results of Stige et al. (2006), who studied 22 cod stocks and did not find strong evidence for density dependent climate effects, i.e. for an interaction between the climate (as represented by the NAO) effect and cod SSB. In contrast, in a study of the 6 main cod stocks in European waters south of $62^{\circ} \mathrm{N}$, Brander (2005a) concluded that the NAO only has a notable effect on recruitment when the SSB is low.

\section{CONCLUSIONS}

The relationship between recruitment, spawning stock biomass, and temperature varied over time. The most frequent alteration in the non-stationary linear models was, for 14 stocks, in the intercept in recruitment success, suggesting a change in prerecruit mortality over time.

Changes in pre-recruit mortality were associated with long-term changes in spawning stock biomass. However, the change in pre-recruit survival generally preceded the change in stock size, suggesting that long-term changes in stock size often are driven by long-term changes in pre-recruit mortality.

A statistically significant threshold in recruitment dynamics was found for 13 stocks; for an additional 14 stocks, threshold models performed better than the best linear or nonlinear stationary models, but the threshold was not statistically significant. The good performance of the threshold models, while not providing evidence for ecological regime shifts, does suggest that abrupt changes are common.

For half of the stocks, the temperature effect was statistically significant when added to the model of the relationship between recruitment success and spawning stock biomass. This includes all the 6 herring stocks studied, with a positive effect for coldwater stocks and negative for stocks in the more temperate southern areas. For plaice, only 4 stocks from around the British Isles were analysed. For all of these stocks, located towards the centre of the overall distribution range of plaice, a tendency toward recruitment being favoured by lower temperatures was found.

Acknowledgements. We are grateful to Prof. C. Möllmann, Dr. M. Lindegren, and 3 anonymous reviewers for constructive, valuable comments to earlier versions of this paper. We thank The Research Council of Norway (RCN) for funding the workshop Tropharct through the MICO project (number 186310, Match/Mismatch and Ecosystem). G.O. and J.M.D. thank RCN for partly funding their contributions to the paper through ADMAR (Adaptive management of living marine resources by integrating different data sources and key ecological processes, number 200497/130), a collaborative project between IMR, Bergen, and CEES, University of Oslo. This work is conducted in association with the IMBER regional program ESSAS (Ecosystem Studies of Sub-Arctic Seas).

\section{LITERATURE CITED}

Akaike H (1974) A new look at the statistical model identification. IEEE Transactions on Automatic Control 19: 716-723

Bailey KM (2000) Shifting control of recruitment of walleye pollock Theragra chalcogramma after a major climatic and ecosystem change. Mar Ecol Prog Ser 198:215-224

Bakun A (2004) Regime shifts. In: Robinson AR, Brink $\mathrm{K}$ (eds) The sea, Vol 13. Harvard University Press, Cambridge, MA

Bakun A (2010) Linking climate to population variability in marine ecosystems characterized by non-simple dynamics: conceptual templates and schematic constructs. J Mar Syst 79:361-373

Beamish RJ, McFarlane GA, Benson A (2006) Longevity overfishing. Prog Oceanogr 68:289-302

> Beaugrand G (2004) The North Sea regime shift: evidence, causes, mechanisms and consequences. Prog Oceanogr 60:245-262 
Berkeley S, Hixon MA, Larson RJ, Love MS (2004) Fisheries sustainability via protection of age structure and spatial distributions of fish populations. Fisheries 29:23-32

Biggs R, Carpenter SR, Brock WA (2009) Turning back from the brink: detecting an impending regime shift in time to avert it. Proc Natl Acad Sci USA 106:826-831

Bochkov YA (1982) Water temperature in the 0-200 m layer in the Kola-Meridian in the Barents Sea, 1900-1981. Sb Nauchn Trud PINRO 46:113-122 (in Russian)

Brander K (2000) Effects of environmental variability on growth and recruitment in cod (Gadus morhua) using a comparative approach. Oceanol Acta 23:485-496

Brander K (2005a) Cod recruitment is strongly affected by climate when stock biomass is low. ICES J Mar Sci 62: 339-343

Brander K (2005b) Spawning and life history information for North Atlantic cod stocks. ICES Coop Res Rep 274. ICES, Copenhagen

Brander K (2010) Cod Gadus morhua and climate change: processes, productivity and prediction. J Fish Biol 77: 1899-1911

Brunel T (2010) Age-structure-dependent recruitment: a meta-analysis applied to Northeast Atlantic fish stocks. ICES J Mar Sci 67:1921-1930

> Brunel T, Boucher J (2007) Long-term trends in fish recruitment in the north-east Atlantic related to climate change. Fish Oceanogr 16:336-349

Cardinale M, Möllmann C, Bartolino V, Casini M and others (2009) Effect of environmental variability and spawner characteristics on the recruitment of Baltic herring Clupea harengus populations. Mar Ecol Prog Ser 388: 221-234

> Chambers RC, Waiwood KG (1996) Maternal and seasonal differences in egg sizes and spawning characteristics of captive Atlantic cod, Gadus morhua. Can J Fish Aquat Sci 53:1986-2003

Checkley D, Alheit J, Oozeki Y, Roy C (eds) (2009) Climate change and small pelagic fish. Cambridge University Press, Cambridge

> Ciannelli L, Fisher JAD, Skern-Mauritzen M, Hunsicker ME, Hidalgo M, Frank KT, Bailey KM (2013) Theory, consequences and evidence of eroding population spatial structure in harvested marine fishes. Mar Ecol Prog Ser 480:227-243

Cushing DH, Horwood JW (1994) The growth and death of fish larvae. J Plankton Res 17:783-800

> Drinkwater KF (2006) The regime shift of the 1920s and 1930s in the North Atlantic. Prog Oceanogr 68:134-151

> Drinkwater KF, Myers RA (1987) Testing predictions of marine fish and shellfish landings from environmental variables. Can J Fish Aquat Sci 44:1568-1573

> Drinkwater KF, Beaugrand G, Kaeriyama M, Kim S and others (2010) On the processes linking climate to ecosystem changes. J Mar Syst 79:374-388

Emeis KC, Finney BP, Ganeshram R, Gutierrez D, Poulsen B, Struck U (2010) Impacts of past climate variability on marine ecosystems: lessons from sediment records. J Mar Syst 79:333-342

> Finney BP, Alheit J, Emeis KC, Field DB, Gutierrez D, Struck $U$ (2010) Paleoecological studies on variability in marine fish populations: a long-term perspective on the impacts of climatic change on marine ecosystems. J Mar Syst 79: 316-326

Fox CJ, Planque BP, Darby CD (2000) Synchrony in the recruitment time-series of plaice (Pleuronectes platessa L) around the United Kingdom and the influence of sea temperature. J Sea Res 44:159-168
Francis RC, Hare SR (1994) Decadal scale regime shifts in the large marine ecosystems of the North-east Pacific: a case for historical science. Fish Oceanogr 3:279-291

Frank KT, Leggett WC (1994) Fisheries ecology in the context of ecological and evolutionary theory. Annu Rev Ecol Syst 25:401-422

Fréchet A, Gauthier J, Schwab P, Lambert Y and others (2009) The status of cod in the Northern Gulf of St. Lawrence (3Pn, 4RS) in 2008. Can Sci Advis Sec Res Doc 2009/090. Department of Fisheries and Oceans, Ottawa

Galbraith PS, Pettipas RG, Chassé J, Gilbert D and others (2009) Physical oceanographic conditions in the Gulf of St. Lawrence in 2008. Can Sci Advis Sec Res Doc 2009/014. Department of Fisheries and Oceans, Ottawa

Hilborn R, Walters CJ (1992) Quantitative fisheries stock assessment. Chapman \& Hall, New York, NY

> Hinrichsen HH, Huwer B, Makarchouk A, Petereit C, Schaber M, Voss R (2011) Climate-driven long-term trends in Baltic Sea oxygen concentrations and the potential consequences for eastern Baltic cod (Gadus morhua). ICES J Mar Sci 68:2019-2028

Hjort J (1914) Fluctuations in the great fisheries of northern Europe viewed in the light of biological research. Rapp P-V Reùn Cons Int Explor Mer 20:1-228

Houde E (1987) Fish early life dynamics and recruitment variability. Am Fish Soc Symp 2:17-29

Houde ED (2008) Emerging from Hjort's shadow. J Northwest Atl Fish Sci 41:53-70

Hsieh CH, Yamauchi A, Nakazawa T, Wang WF (2010) Fishing effects on age and spatial structures undermine population stability of fishes. Aquat Sci 72:165-178

Hurvich CM, Tsai CL (1989) Regression and time series model selection in small samples. Biometrika 76:297-307

Iles TC (1994) A review of stock recruitment relationships with reference to flatfish populations. Neth J Sea Res 32: 399-420

Johansen R (2007) A model for the interaction between gadoid larvae and their nauplii prey. Math Biosci 208: 177-192

Kempf A, Dingsør GE, Huse G, Vinther M, Floeter J, Temming A (2010) The importance of predator-prey overlap: predicting North Sea cod recovery with a multispecies assessment model. ICES J Mar Sci 67:1989-1997

Kendall AWJ, Duker GJ (1998) The development of recruitment fisheries oceanography in the United States. Fish Oceanogr 7:69-88

Kjesbu OS, Kryvi H, Sundby S, Solemdal P (1992) Buoyancy variations in eggs of Atlantic cod (Gadus morhua L.) in relation to chorion thickness and egg size: theory and observations. J Fish Biol 41:581-599

Kjesbu OS, Solemdal P, Bratland P, Fonn M (1996) Variation in annual egg production in individual captive Atlantic cod (Gadus morhua). Can J Fish Aquat Sci 53:610-620

Koslow J (1992) Fecundity and the stock-recruitment relationship. Can J Fish Aquat Sci 49:210-217

Köster FW, Hinrichsen HH, Schnack D, St John MA and others (2003) Recruitment of Baltic cod and sprat stocks: identification of critical life stages and incorporation of environmental variability into stock-recruitment relationships. Sci Mar 67:129-154

Köster FW, Möllmann C, Hinrichsen HH, Wieland K and others (2005) Baltic cod recruitment-the impact of climate variability on key processes. ICES J Mar Sci 62: 1408-1425

Law R (1991) Fishing in evolutionary waters. New Sci 1758: 35-37 
Levi D, Andreoli MG, Bonanno A, Fiorentino F and others (2003) Embedding sea surface temperature anomalies into the stock recruitment relationship of red mullet (Mullus barbatus L. 1758) in the Strait of Sicily. Sci Mar 67:259-268

Lindegren M, Möllmann C, Nielsen A, Brander K, MacKenzie BR, Stenseth NC (2010) Ecological forecasting under climate change: the case of Baltic cod. Proc Biol Sci 277 : 2121-2130

Liu H, Ciannelli L, Decker MB, Ladd C, Chan KS (2011) Nonparametric threshold model of zero-inflated spatiotemporal data with application to shifts in jellyfish distribution. J Agric Biol Environ Stat 16:185-201

Loeng H, Bjørke H, Ottersen G (1995) Larval fish growth in the Barents Sea. In: Beamish RJ (ed) Climate change and northern fish populations. Can Spec Publ Fish Aquat Sci 121:691-698

> Marteinsdottir G, Thorarinsson K (1998) Improving the stock-recruitment relationship in Icelandic cod (Gadus morhua L.) by including age diversity of spawners. Can J Fish Aquat Sci 55:1372-1377

Meekan MG, Fortier L (1996) Selection for fast growth during the larval life of Atlantic cod Gadus morhua on the Scotian Shelf. Mar Ecol Prog Ser 137:25-37

Möllmann C, Diekmann R, Müller-Karulis B, Kornilovs G, Plikshs M, Axe P (2009) Reorganization of a large marine ecosystem due to atmospheric and anthropogenic pressure: a discontinuous regime shift in the Central Baltic Sea. Glob Change Biol 15:1377-1393

Morgan MJ, Shelton PA, Brattey J (2007) Age composition of the spawning stock does not always influence recruitment. J Northwest Atl Fish Sci 38:1-12

Mueter FJ, Boldt JL, Megrey BA, Peterman RM (2007) Recruitment and survival of Northeast Pacific Ocean fish stocks: temporal trends, covariation, and regime shifts. Can J Fish Aquat Sci 64:911-927

Myers RA (1998) When do environment-recruitment correlations work? Rev Fish Biol Fish 8:285-305

Myers RA, Barrowman NJ (1996) Is fish recruitment related to spawner abundance? Fish Bull 94:707-724

> Olsen EM, Ottersen G, Llope M, Chan KS, Beaugrand G, Stenseth NC (2011) Spawning stock and recruitment in North Sea cod shaped by food and climate. Proc Biol Sci 278:504-510

> Ottersen G (2008) Pronounced long-term juvenation in the spawning stock of Arcto-Norwegian cod (Gadus morhua) and possible consequences for recruitment. Can J Fish Aquat Sci 65:523-534

> Ottersen G, Stenseth NC (2001) Atlantic climate governs oceanographic and ecological variability in the Barents Sea. Limnol Oceanogr 46:1774-1780

> Ottersen G, Helle K, Bogstad B (2002) Do abiotic mechanisms determine interannual variability in length-at-age of juvenile Arcto-Norwegian cod? Can J Fish Aquat Sci 59:57-65

> Ottersen G, Hjermann D, Stenseth NC (2006) Changes in spawning stock structure strengthens the link between climate and recruitment in a heavily fished cod stock. Fish Oceanogr 15:230-243

Planque B, Fredou T (1999) Temperature and the recruitment of Atlantic cod (Gadus morhua). Can J Fish Aquat Sci 56:2069-2077

Planque B, Fromentin JM, Cury P, Drinkwater KF, Jennings S, Perry RI, Kifani S (2010) How does fishing alter marine populations and ecosystems sensitivity to climate? J Mar Syst 79:403-417
Ponomarenko VP (1973) On a probable relation between age composition of spawning stock and abundance of the year classes of cod in the Barents Sea. Rapp P-V Reun Cons Int Explor Mer 164:69-72

Power D, Morgan J, Murphy EF, Brattey J, Healey B (2010) An assessment of the cod stock in NAFO Divisions 3NO. In: SCR Doc 2010/42. Northwest Atlantic Fisheries Organization

R Development Core Team (2010) R: a language and environment for statistical computing. R Foundation for Statistical Computing, Vienna

Ricker WE (1954) Stock and recruitment. J Fish Res Board Can 11:559-623

Rothschild BI (1986) Dynamics of marine fish populations. Harvard University Press, Cambridge, MA

> Sætersdal G, Loeng H (1987) Ecological adaption of reproduction in Northeast Arctic cod. Fish Res 5:253-270

Shelton PA, Sinclair AF, Chouinard GA, Mohn R, Duplisea DE (2006) Fishing under low productivity conditions is further delaying recovery of Northwest Atlantic cod (Gadus morhua). Can J Fish Aquat Sci 63:235-238

- Shepherd J (1999) Extended survivors analysis: an improved method for the analysis of catch-at-age data and abundance indices. ICES J Mar Sci 56:584-591

Stige LC, Ottersen G, Brander K, Chan KS, Stenseth NC (2006) Cod and climate: effect of the North Atlantic Oscillation on recruitment in the North Atlantic. Mar Ecol Prog Ser 325:227-241

> Stige LC, Ottersen G, Dalpadado P, Chan KS and others (2010) Direct and indirect climate forcing in a multispecies marine system. Proc Biol Sci 277:3411-3420

Stige LC, Hunsicker ME, Bailey KM, Yaragina NA, Hunt GL Jr (2013) Predicting fish recruitment from juvenile abundance and environmental indices. Mar Ecol Prog Ser 480:245-261

> Svendsen E, Skogen M, Budgell P, Huse G and others (2007) An ecosystem modeling approach to predicting cod recruitment. Deep-Sea Res II 54:2810-2821

Swain DP, Currie LG, Chouinard GA, Poirier GA, Savoie L, Hurlbut T, Daigle D (2007) Assessment of the southern Gulf of St. Lawrence cod stock, March 2007. CSAS Res Doc 2007/033. Department of Fisheries and Oceans, Ottawa

Tereshchenko VV (1996) Seasonal and year-to-year variations of temperature and salinity along the Kola meridian transect. ICES CM C:11, p 24

Trippel EA, Kjesbu OS, Solemdal P (1997) Effects of adult age and size structure on reproductive output in marine fishes. In: Chambers RC, Trippel EA (eds) Early life history and recruitment in fish populations. Chapman \& Hall, London

> Vincenzi S, Satterthwaite WH, Mangel M (2012) Spatial and temporal scale of density-dependent body growth and its implications for recruitment, population dynamics and management of stream-dwelling salmonid populations. Rev Fish Biol Fish 22:813-825

Walters C, Kitchell JF (2001) Cultivation/depensation effects on juvenile survival and recruitment: implications for the theory of fishing. Can J Fish Aquat Sci 58:39-50

Wang Y, O'Brien L, Clark K, Gavaris S, Hatt B (2009) Assessment of Eastern Georges Bank Atlantic cod for 2009. In: Ref Doc 2009/01. Transboundary Resource Assessment Committee, Fisheries and Oceans Canada, St. Andrews, NB

Wood SN (2006) Generalized additive models: an introduction with R. Chapman \& Hall/CRC Press, Boca Raton, FL 
Appendix 1
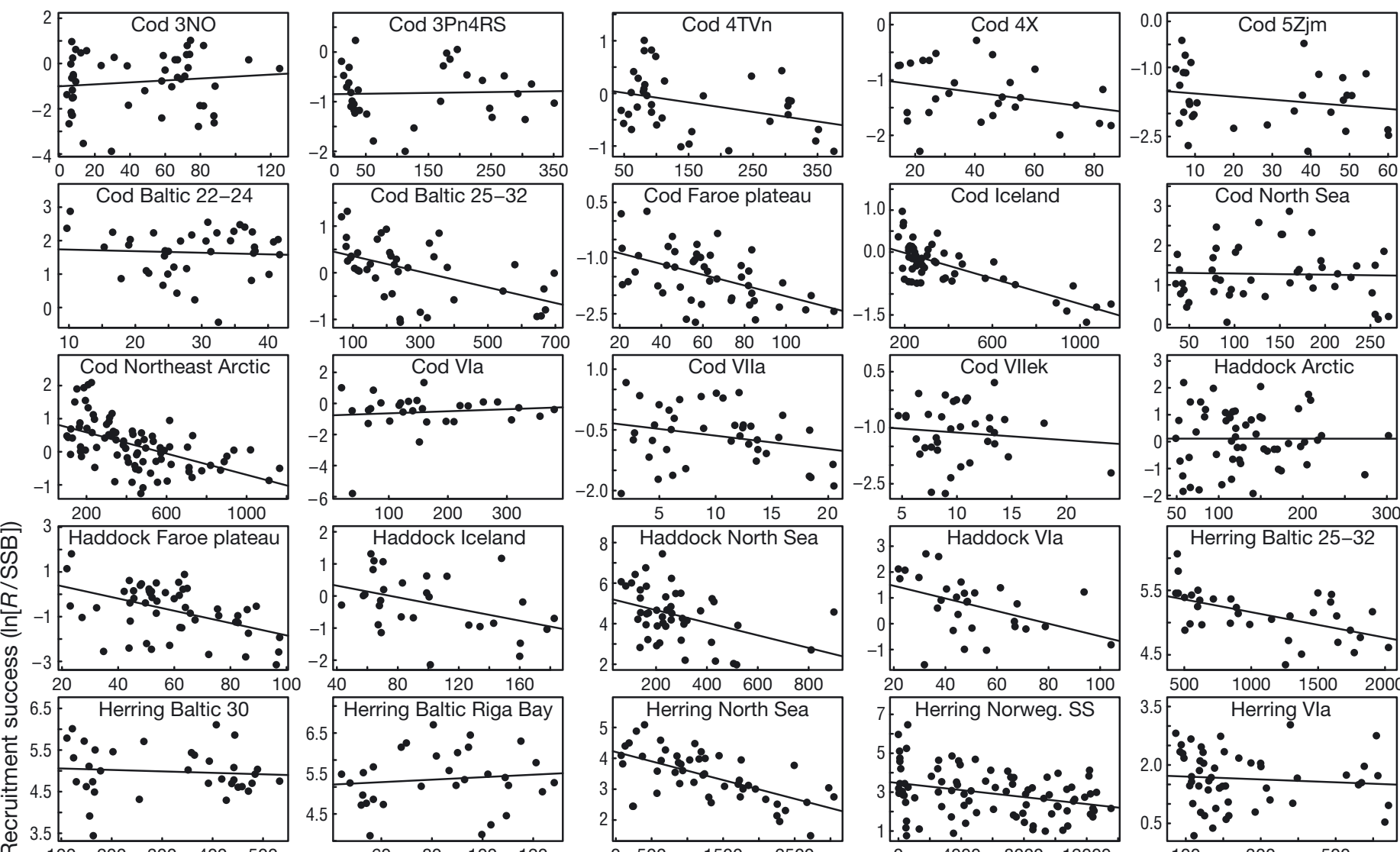

$\begin{array}{lllll}100 & 200 & 300 & 400 & 500\end{array}$

3 Plaice North Sea
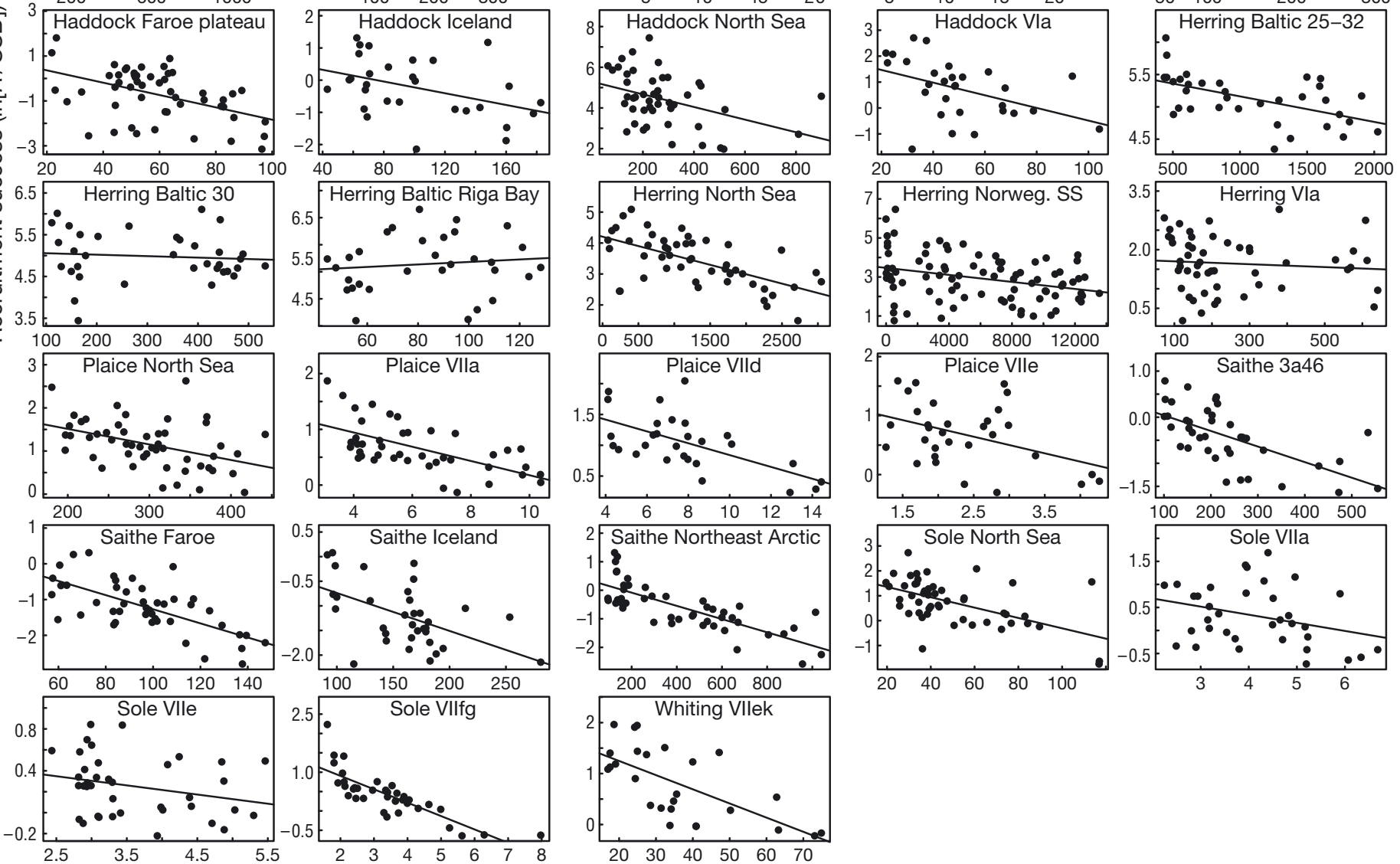

Spawning stock biomass (1000 t)

Fig. A1. Recruitment success as a function of spawning stock biomass (SSB) for 38 North Atlantic fish stocks. Recruitment success is measured as the natural logarithm of the fraction of the number of recruits $(R, 1000 \mathrm{~s})$ on SSB (t). According to Ricker's spawner-recruit model (Ricker 1954), this log-fraction declines as a linear function of SSB, where stronger negative slope means stronger compensatory density dependence 